\title{
Assessing Manual Wheelchair Caster Design for Mobility in Winter \\ Conditions
}

\author{
By \\ Michele Berthelette
}

A thesis submitted to the faculty of Graduate Studies of

The University of Manitoba

In partial fulfilment of the requirements of the degree of

Master of Science

Department of Biosystems Engineering

University of Manitoba

Winnipeg

Copyright (C) 2016 Michele Berthelette 


\section{Abstract}

Many manual wheelchair users who live in cold climates are faced with daily difficulties related to personal independence and societal inclusion, as their assistive devices are unable to overcome the physical barriers created by snow and ice. Packed snow on sidewalks creates a barrier for wheelchair users as the small caster wheels become embedded in the snow-pack, which leads to upper body fatigue as well as wheelchair tipping and falling. The purpose of this thesis was to develop a method with which the best design could be determined of a group of four commercially available manual wheelchair casters (Solid, Pneumatic, Wheel Blades, and FreeWheel). This method was developed based on the HAAT model of assistive technology design. It was confirmed that snow-packed surfaces, as well as increased inclines, had a significant detrimental effect on the recorded human factors determinants, and further analysis revealed that caster type being used did have a significant effect on some of the measures collected. Performance time suffered significantly on snow-packed conditions (Mean $=17.8 \mathrm{~s}$ ) versus bare wheeling surface (Mean $=7.2 \mathrm{~s}$ ). Ratings of perceived exertion were significantly affected by caster type, where the FreeWheel had a lower rating (1.4/10) than the other caster types (2.8/10). Finally, caster penetration of both the WheelBlades and the FreeWheel into the snow pack was found to be significantly similar to bare surface conditions at an average of 1.3 $\mathrm{mm}$ of penetration compared to tradition solid casters that had a mean penetration of $11.7 \mathrm{~mm}$. While some results did not have statistically significant effects, trends were observed that indicate that the FreeWheel caster type had improved performance over the other casters. 


\section{Acknowledgments}

I would like to express my deepest thanks to my advisors Dr. Danny Mann, Dr. Jacquie Ripat, and Dr. Cheryl Glazebrook. Their support and guidance are what have made this project successful, and through their patience and kindness I feel as though I have grown academically and as an individual. Thank you to my friends and family, for their love and support for the duration of my studies. 


\section{Table of Contents}

Signature Page

Error! Bookmark not defined.

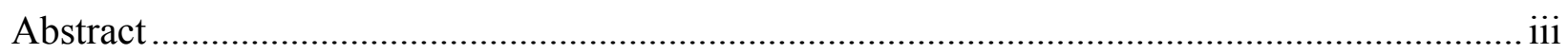

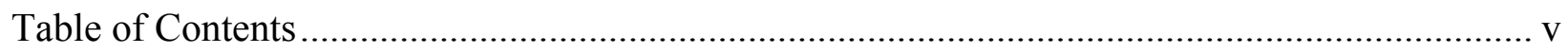

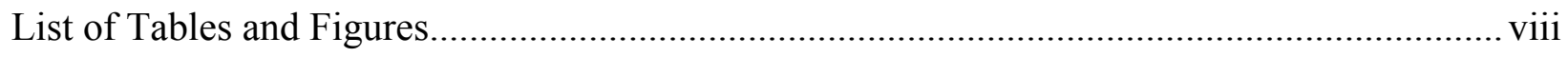

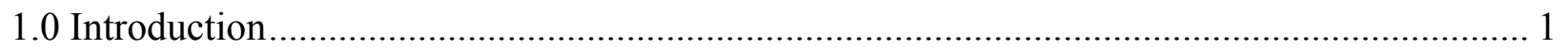

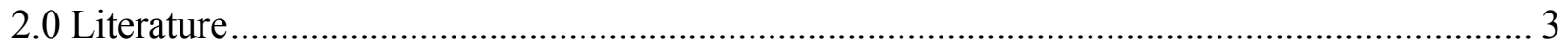

2.1 Model for Assistive Technology Selection and Design .......................................................... 3

2.2 Caster Design and Wheelchair-Related Accidents .................................................................... 4

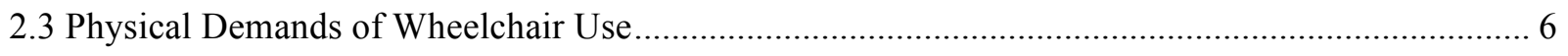

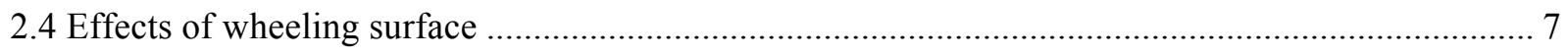

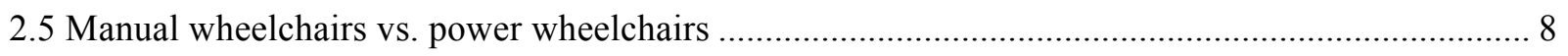

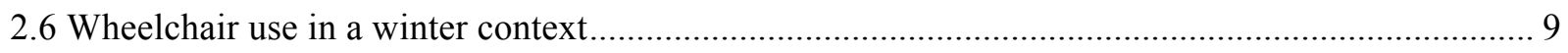

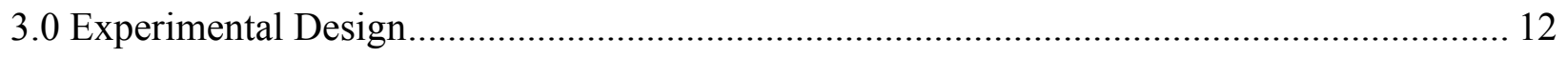

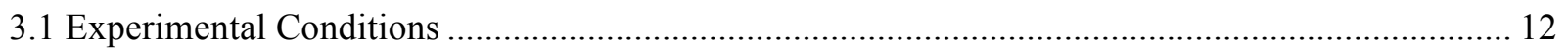

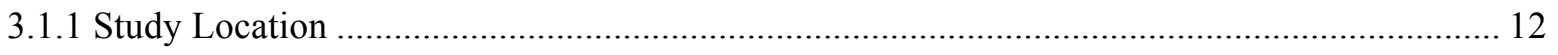

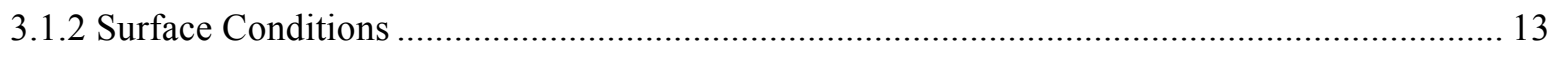

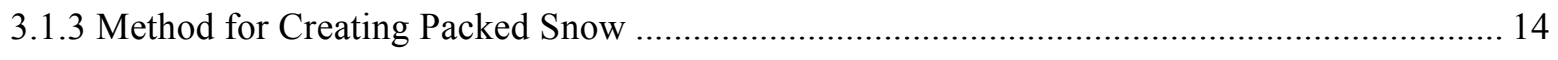

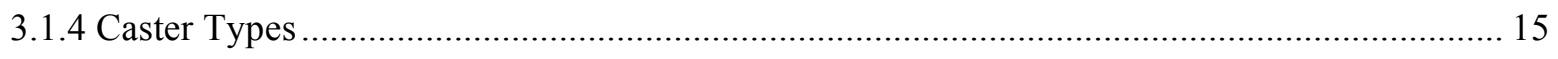

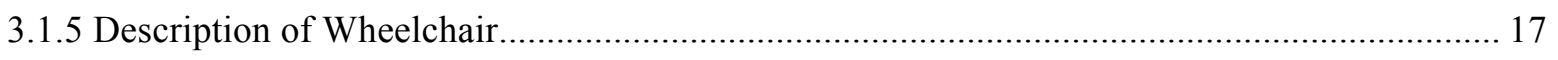

3.2 Experimental Phase 1 - Human Performance ................................................................... 18

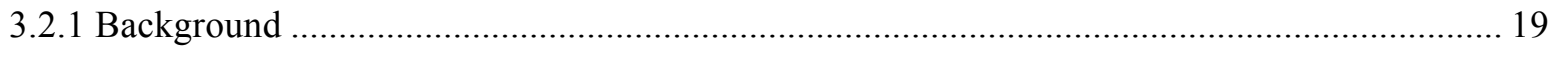




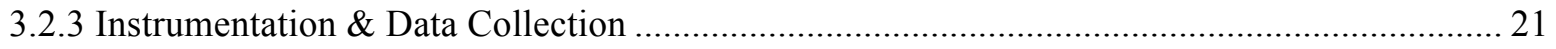

3.3 Experimental Phase 2 - Mechanical Performance .................................................................... 23

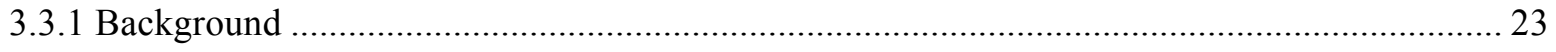

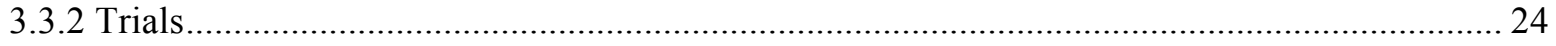

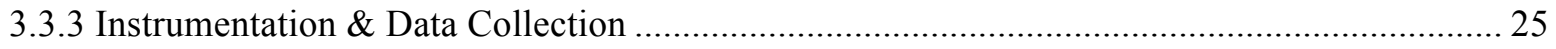

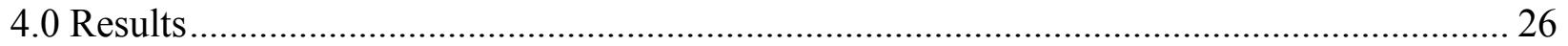

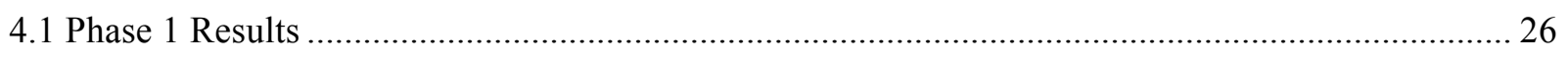

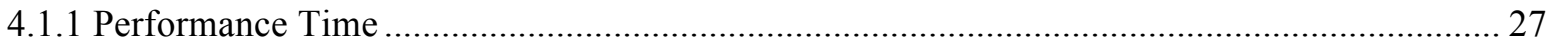

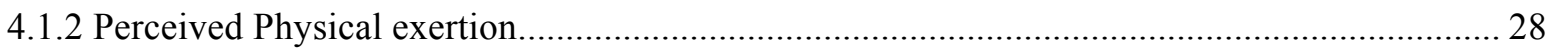

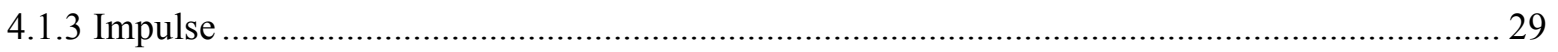

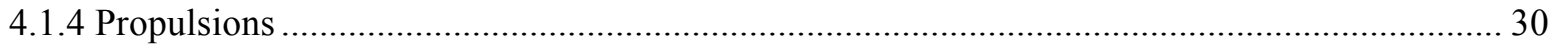

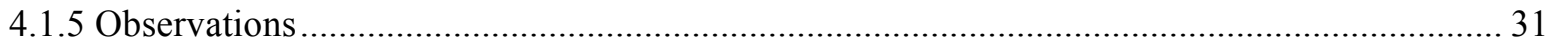

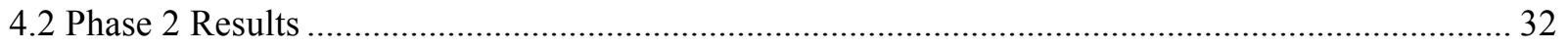

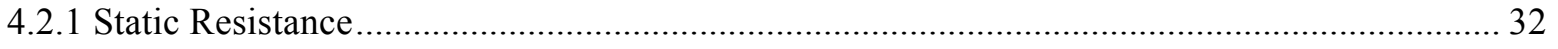

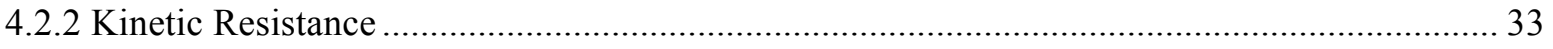

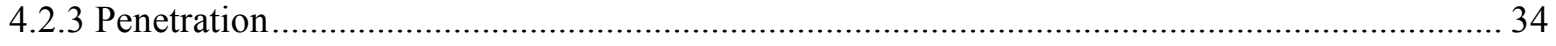

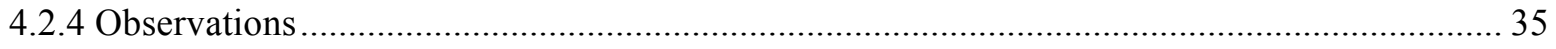

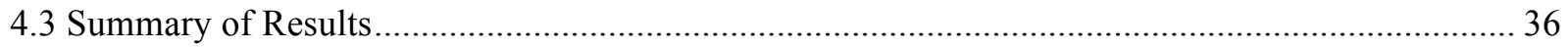

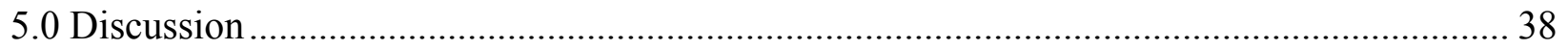

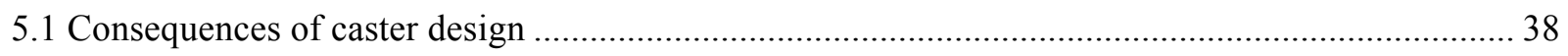

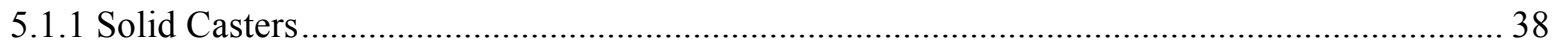

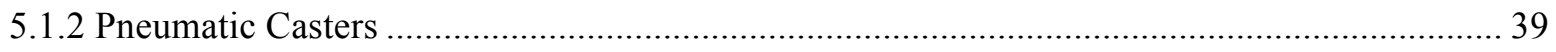

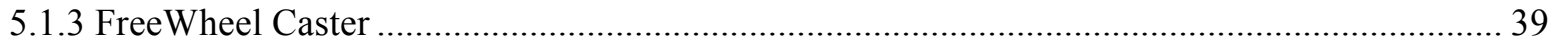

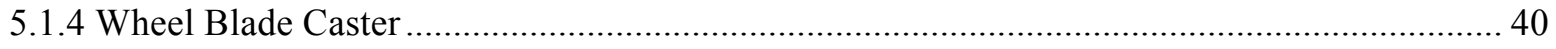




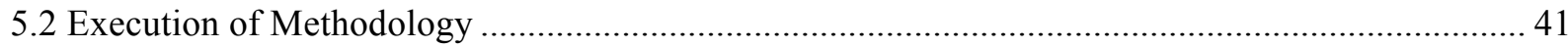

5.2.1 Appropriateness of performance measures ..................................................................... 41

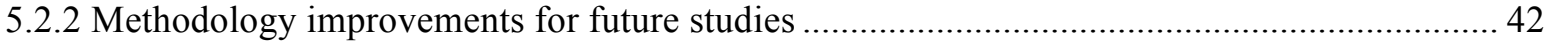

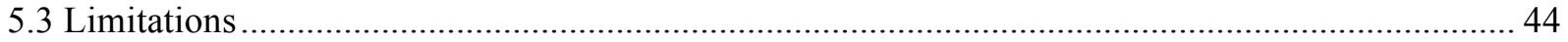

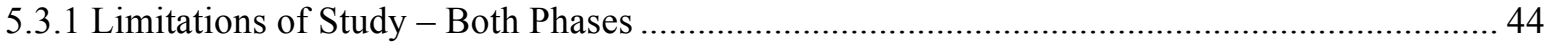

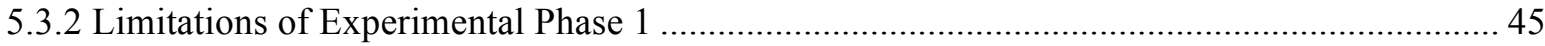

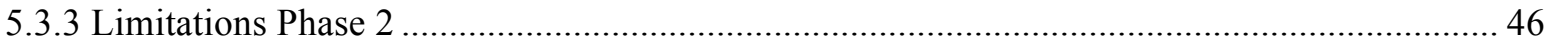

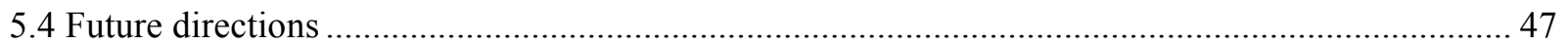

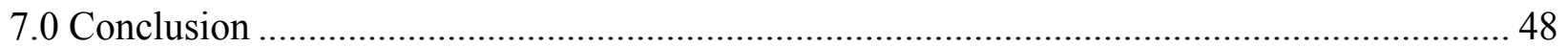

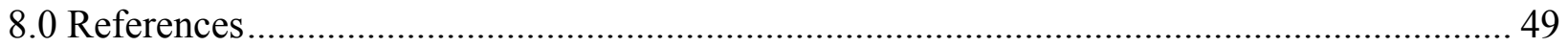

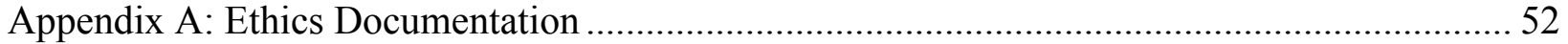

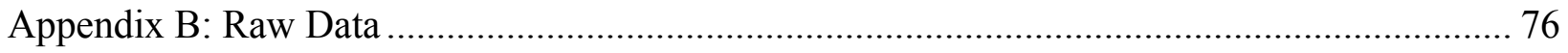




\section{List of Tables and Figures}

Figure 1 Inclined (back) and flat (front) experimental setup ............................................... 14

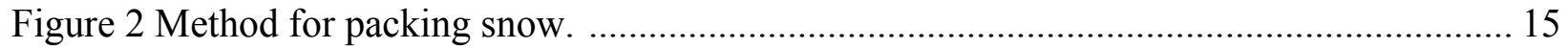

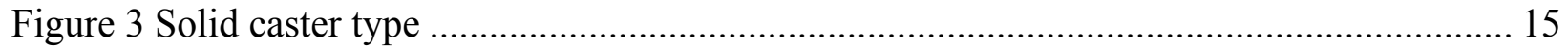

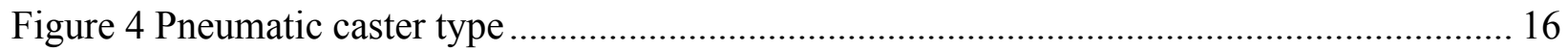

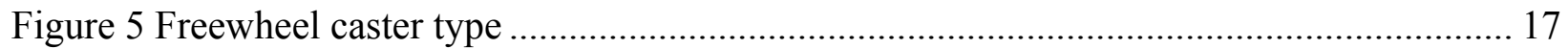

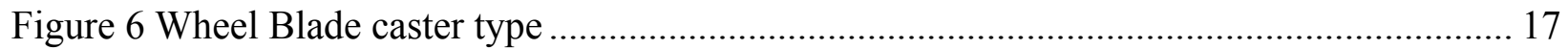

Figure 7 Sunrise Medical Quickie GPV manual wheelchair ................................................... 18

Figure 8 Force sensor placements on the palm of the hand ............................................... 22

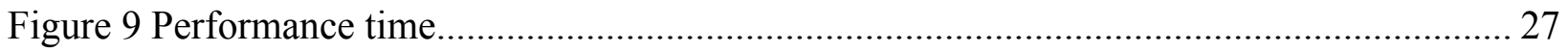

Figure 10 Borg's rating of perceived physical exertion...................................................... 28

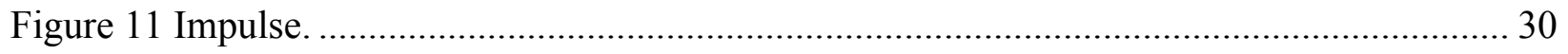

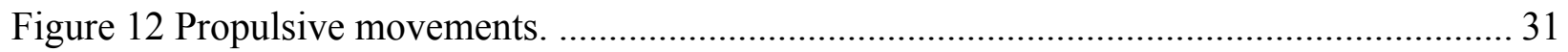

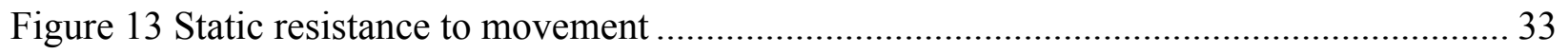

Figure 14 Kinetic resistance to movement..................................................................... 34

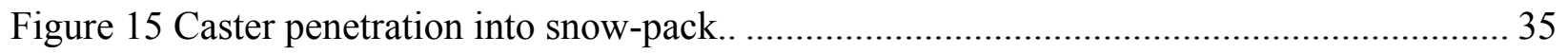

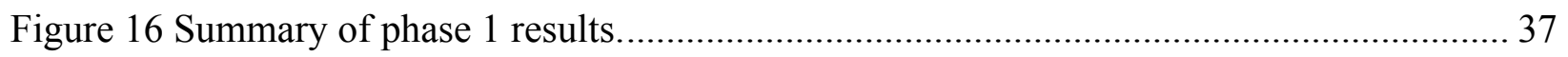

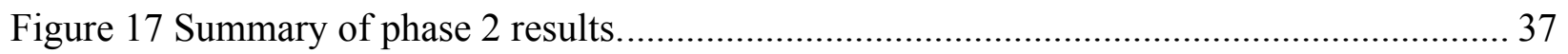




\subsection{Introduction}

Many manual wheelchair users who live in cold climates are faced with daily problems related to personal independence and societal inclusion, as their wheelchairs are unable to overcome the physical barriers created by snow and ice. Simply clearing snow from walkways may be a feasible solution for the homes of these individuals who use wheeled mobility devices (WMDs). However, clearing snow is not a reliable solution in public areas, as many northern cities are not required to expose bare sidewalks, but rather the snow clearing procedure leaves a layer of packed snow that pedestrians are able to walk on. Packed snow on sidewalks creates a barrier for many individuals using WMDs as the small caster wheels become embedded in the snow-pack, which may lead to wheelchair tipping and falling.

In the following thesis a methodology for assessing the performance of wheelchair casters has been created following the HAAT model of assistive technology design. In the first phase of the study there was a focus on the human user, and performance measures affecting the individual using the wheelchair. In the second phase of the study, there was a focus on the interactions between the caster wheels and the wheeling surface of packed snow. In this thesis, the methodology was developed to test manual wheelchair casters on packed snow conditions, however, it may be modified to test new designs, different wheelchair components, or even different surface types.

The objective of this thesis is to determine which manual wheelchair caster design elements are most appropriate for use in a winter context, and to determine whether adapting wheelchair casters could return an individual to an equal level of functioning as though there existed no winter barriers. A methodology was developed to assess the performance of a manual wheelchair under winter conditions focusing on both human factors and conventional engineering 
determinants. Performance measures were based on human capabilities, and the way in which the wheelchair interfaces with the wheeling surface.

In addition to studying the wheelchair casters, the assessment method was critically analyzed for its ability to accurately evaluate the performance of manual wheelchairs. The importance of critically analyzing the methodology is that it will aid in determining whether it could be used in future studies focused on different manual wheelchair components. 


\subsection{Literature}

While much research has been done in the area of wheeled mobility in general, very limited literature exists on the topic of winter wheeled mobility. The following sections will explore the model for assistive technology selection design, manual wheelchair related accidents and injuries, and wheelchair use in adverse environments (including a winter context).

\subsection{Model for Assistive Technology Selection and Design}

Many individuals with disability require the use of assistive technology to maintain an independent lifestyle. Assistive technology that is properly chosen and fitted to an individual's abilities and needs has the potential to positively influence their life in many ways. There exists the HAAT model of assistive technology selection and design, which takes a human centered approach (Cook and Polgar, 2015). HAAT is an acronym that stands for human, activity, assistive technology, and context, this means an assistive technology is designed for the human first, an individual with specific abilities and needs who wishes to perform an activity within a specific context. In the case of the HAAT model the context encompasses not only the physical environment, but also the social and cultural context as well. Once all considerations of the individual's body function, needs, and environmental context are taken into account, an assistive technology is recommended or designed. Many commercially available technologies attempt to be universally usable by all individuals, but often when designing universally a minority of individuals are not considered. Often, assistive technology designers miss the subtleties of both environmental as well as cultural contexts. This has been a situation in creating a need for mobility devices that are capable of overcoming the barriers associated within a Canadian winter context. Technology that is appropriate for an individual living in the southern United States is 
not necessarily appropriate for an individual who lives in a northern climate that experiences five months of snow per year.

The World health Organization's International classification of functioning follows a similar framework to the HAAT model. While taking into account the individual's body function and structure, the aim of health care practitioners is to return them to participating in activities socially, as well as functioning in every-day living (World Health Organization, 2012).

\subsection{Caster Design and Wheelchair-Related Accidents}

Many studies have been performed which focused on manual wheelchair configuration and user safety, there have been conflicting results on the role that casters have on mobility over various terrain types. While the focus of this thesis is manual wheelchair design it is important to note that other mobility options for winter mobility exist such as power wheelchairs and power assisted manual wheelchairs.

Gaal and Rebholtz (1997) conducted a phone survey of wheelchair users living in urban areas $(n=109)$, which focused on wheelchair configuration and stability and identified a relationship between wheelchair caster type and stability. Gaal and Rebholtz found that, for manual wheelchair users, $79 \%$ of tips and falls occurred on non-level ground and that small and solid casters were associated with tips and falls $(\mathrm{p}=0.024)$. Many survey respondents reported that tips and falls were usually a result of the footrests and front wheels being slowed or stopped by terrain, creating a tipping moment when the front portion of the wheelchair is suddenly stopped. This survey was not conducted with a population that was exposed to snow and ice (San Francisco), however, it is reasonable these findings could be applied in a winter terrain 
scenario as it is likely that the results of this study would be exaggerated when considering mobility on packed snow.

Lemaire et al. (2010) performed a study on wheelchair navigation in winter conditions, where participants were required to ascend and descend a snow-covered ramp in a manual wheelchair. Lemaire et al. observed similar phenomena described by Gaal and Rebholtz in their 1997 study. They observed the front caster wheels of manual wheelchairs becoming stuck and digging into the packed snow and preventing forward progression. At that point, participants would perform potentially dangerous maneuvers to allow the front casters to become unstuck. However, casters did not become embedded when the ramp was ice-covered. Overall though, this study did not find any relationship between successful ramp ascent/descent and caster size.

A survey of non-institutionalized manual wheelchair users performed by Kirby et al. (1994) in Nova Scotia revealed that more than twice as many accidents occurred outdoors as indoors. In one case, the participant reported falling out of his chair and sustained frostbite while dragging himself to safety. A recent study performed by Ripat et al. (2015) surveyed wheeled mobility device users in Manitoba specifically on their mobility and community participation during winter months. The majority of the respondents $(\mathrm{n}=99)$ in Ripat et al.'s study experienced their tires and casters becoming stuck in snow (95\%), and many identified issues with sidewalks and roads (99\%). Fifty percent of respondents believed that wheelchair vendors, manufacturers and health care providers have a role to play in addressing winter-related issues. The study concludes that among other changes related to snow clearing practices, there is an existing need for improved wheelchair designs for use in winter conditions. Similar studies performed by Lindsay and Yantzi (2014) in Ontario, as well as Shirado et al. (1995) in Hokkaido, Japan found similar results. All identified a need for improved wheelchair tire and caster design; for the safety 
and community participation using wheeled mobility devices in winter conditions. From the results of these studies it is clear that the standard caster design is not well suited for use in winter conditions.

\subsection{Physical Demands of Wheelchair Use}

Mechanical stresses and high load bearing in the upper limbs associated with manual wheelchair use is believed to be associated with chronic shoulder injuries such as arthritis, and repetitive strain injury (Veeger et al., 2002). However, as an alternative to manual wheelchair use, individuals who use power wheelchairs are at risk of secondary illnesses such as obesity due to inactivity. Actions taken to decrease biomechanical stresses, such as decreasing rolling resistance of the wheelchair and decreasing the forces necessary to propel manual wheelchairs could have long-term benefits for manual wheelchair users. However, it is important to recognize that sometimes there isn't a choice and powered wheelchair use is necessary.

Previous studies have identified increased biomechanical stresses associated with incline, wheeling surface, and wheelchair configuration, and certain wheelchair maneuvers. A study performed by Marrow et al. (2010) found that the maneuver that created the greatest internal joint force was weight relief movements, however, these movements were not as commonly performed as propulsion movements, and do not create as great of a risk for repetitive strain injury. In the same study upper limb joint force levels were ranked from highest to lowest in this order: weight relief movements followed by inclined propulsion condition, start up and stopping condition, and lowest joint forces were experienced with level propulsion. Start-up propulsions are associated with relatively high forces, and while they happen occasionally on indoor and smooth surfaces, frequent stopping is known to happen on softer outdoor surfaces such as grass, leading to increased likelihoods of upper body injury (Koontz et al., 2005). Decreasing the forces 
associated with incline, surface, and certain maneuvers could lead to decreased injury in wheelchair users.

\subsection{Effects of wheeling surface}

Previous studies have identified a relationship between wheeling surface characteristics and the overall effort required to use a manual wheelchair. Incline and surface roughness are usually two characteristics that are commonly researched.

A study performed by Choi et al. (2014) found that simply by wheeling on a slope of 1:10 versus 1:12 significantly affected biological markers for exertion such as blood pressure and heart rate. It was also found that an increase in slope significantly increased the performance time of ascending a ramp for scenarios where the wheelchair user was propelling themselves as well as when a caregiver was pushing the individual in the wheelchair. In a similar study by Hurd et al. (2009), it was found that the presence of a $3^{\circ}$ slope had a significant detrimental effect on the amount of propulsive movements required as well as the work required of the individual to provide.

Not only does incline affect the biological strain of wheelchair use, but the surface texture and roughness also impact strain. The study by Hurd et al. (2009) found that there were significantly increased work and propulsive movements required for ambulation on aggregate concrete compared to smooth concrete. While there may be very small difference between the impact of smooth and aggregate concrete for walking as a pedestrian, clearly it affects the performance of wheelchair users. Koontz et al. (2005) performed a similar study where they examined various indoor and outdoor surface types. Koontz found that when wheeling on grass surfaces, significantly increased wheel torque was produced and decreased distance traveled over 
time compared to the reference surface of smooth concrete. Koontz concluded that wheeling on outdoor surfaces could lead to upper-body injury, and that alternative technologies should be considered.

Simply by wheeling on inclined slopes or textured surfaces there is a significant increase in biomechanical strain, stroke count, and a significant difference in overall velocity. Previous studies have examined wheeling surfaces associated with indoor or mild climate environments, but very few have addressed packed snow or ice conditions.

\subsection{Manual wheelchairs vs. power wheelchairs}

When faced with adverse conditions such as those created by winter conditions, many health care professionals will suggest that individuals with mobility disabilities change the mobility devices that they use. "Progressing" to the next level of mobility aide is one approach, in this case ceasing to use a manual wheelchair and instead using a power wheelchair would likely be suggested. Using a power wheelchair instead of a manual wheelchair allows individuals to overcome many barriers associated with winter conditions. Power wheelchair users will be able to travel greater distances with much less propulsion effort than manual wheelchair users, and will avoid side effects of manual wheelchair use such as repetitive strain injury of the upper limbs and chronic shoulder pain (Veegar et al., 2002).

While changing to a power wheelchair may help with completing functional activities, there are many other factors at play that will ultimately affect the individual user. Transitioning from a manual wheelchair to a power wheelchair is not easy and many life-altering changes need to be made. Considerations that need to be taken are the learning curve of power wheelchair use, adapting one's home and transportation to accommodate the increased size, decreased activity 
levels that could lead to obesity, and finally self-stigmatization which could lead to further isolating behavior (Cook and Polgar, 2015). A study performed in Illinois confirmed that individuals who used manual wheelchairs for mobility had increased self-esteem and perceived independence over those who used power wheelchairs (Salentine, 2012).

Finally, it is of note that the use of power wheelchairs does not entirely relieve the barriers associated with winter, but rather creates new ones. In the studies of Ripat et al. (2015) and Linsday and Yantzi (2014), power wheelchair users reported issues with reduced battery life and electronics impacted due to the sub-zero temperatures. It was also found that when power wheelchair batteries die or tires become stuck in snow, power wheelchairs are more difficult to move due to their increased weight. Manual wheelchair users are at an advantage in this situation, as a caregiver will be able to assist them in overcoming difficult barriers that occur due to winter conditions, whereas power wheelchairs are too heavy for a caregiver to handle.

\subsection{Wheelchair use in a winter context}

Most individuals living in Canada will experience sub-zero conditions and wheeling surfaces such as packed snow and ice every year in varying levels of severity. Many individuals will experience decreased community participation in the wintertime due to incompatibilities between their wheeled mobility devices and the environment in which they are being used. In Canada there are 1.2 million people who use mobility aides to participate in their community and society. In 2012, 7.2\% of Canadians reported a mobility disability, which becomes more prevalent with age (Statistics Canada, 2012). Issues with using mobility devices in winter conditions need to be addressed to ensure community participation throughout the winter months for an increased quality of life, and to ensure the safety of those who must go outdoors in the winter months to attend doctor's appointments or other mandatory tasks. 
In Winnipeg, Manitoba even the highest priority sidewalks do not have complete snow removal, but rather are maintained as a compacted snow surface (City of Winnipeg Policy, 2011). While it is easy for pedestrians to continue to walk on compacted snow surfaces, wheelchair users often struggle to maintain their mobility. Wheels and casters will penetrate into the snow pack, creating torques or tipping moments, which has a potential for injury or for wheelchair users to be stranded outdoors (Lindsay and Yantzi, 2014). Many individuals will choose to use their wheelchairs on cleared roads instead of the sidewalks, which put them at risk to be involved in a collision with a motor vehicle accident. While one solution to wheeled mobility issues in winter conditions would be to improve snow-clearing practices, it involves large monetary and resource allocation for rather small population. It would be most realistic to select the appropriate technology to be more effective in packed snow walkway conditions, as many of the affected individuals also live in rural/northern communities where snow clearing may happen infrequently. Additionally, it should be considered that local culture celebrates the winter and snow. In Manitoba many individuals are unable to participate in activities and festivals such as Festival du Voyageur, Trappers Festival, or The Forks River Trail due to the wheeling surfaces that they will encounter. Additionally, many common winter activities will be inaccessible to individuals using manual wheelchairs, for example winter walking trails or snow play. One of the youth respondents in the Lindsay and Yantzi study (2014) spoke of how he enjoyed participating in snowball fights with his friends, even though he was more likely to be hit than the others. Young people who are afraid to or are unable to play outside are missing out on an important opportunity for having fun physical activity and to create a Canadian identity. Simply clearing snow will not allow individuals to fully participate in their local culture and 
community. According to the HAAT model, assistive technologies should cater to the context and activities which the human user choses to perform.

Winter conditions can also be the cause of negative social and psychological effects on individuals using mobility devices. The recent study performed by Linsay and Yantzi (2014) reported that many individuals experience worry and fear over going outside, and the possibility of becoming stranded due to snow conditions. The study performed by Ripat et al. found that WMD users reported decreased independence, where $88 \%$ of survey respondents reported an additional need for assistance during the winter months as compared to summer months. As a result of winter mobility issues, $68 \%$ of the 99 respondents required additional assistance maintaining outing frequency during the winter months. Worry and the challenges of outdoor conditions could eventually lead to decreased community participation, isolation, and ultimately a decreased quality of life. It is clear that the physical barriers created by winter conditions that individuals who use wheelchairs face has a negative influence on their psychological and social wellbeing, and that with improved assistive technology design individuals will be able to overcome the physical barriers associated with winter and regain their independence. 


\subsection{Experimental Design}

The experiment was divided into two phases that were carried out over the course of two winters (2015 and 2016). The experiments focused on assessing the performance of four commercially available wheelchair casters in snow-packed conditions. A testing method was designed and used to assess wheelchair performance on packed-snow conditions. Phase one of the experiment focused more so on human performance while using the different caster types, whereas phase two focused on mechanical performance of the wheelchair itself while using different caster types. Both phases of the experiment used the same surface conditions and caster types, which will be further explained in the sections below.

\subsection{Experimental Conditions}

Similar experimental conditions were created for both phases of the study. The following sections will cover the location in which the experiments were conducted, the methods for creating the packed snow conditions, and a description of the commercially available caster types that were investigated.

\subsubsection{Study Location}

The two experiments took place in a non-insulated building, which provided shelter from the wind, on the University of Manitoba Fort Garry campus. The first phase experiment took place between the dates of February 11 - March 10, 2015 with temperatures ranging between -21 to $8^{\circ} \mathrm{C}$ with a mean temperature of $-7.4^{\circ} \mathrm{C}$. The second phase experiment took place between January $28-31,2016$ with temperatures between $-2^{\circ} \mathrm{C}$ to $0^{\circ} \mathrm{C}$ with a mean of $-1^{\circ} \mathrm{C}$. Temperature was measured inside of the building at the time of data collection. 


\subsubsection{Surface Conditions}

Four experimental surface conditions were created: i) snow-packed with no incline, ii) snow-packed with a 1:12 incline, iii) bare concrete with no incline, and iv) bare ramp with a 1:12 incline.

The ramp used for this study adhered to the City of Winnipeg accessibility standards; it had two sets of handrails, and finished on a $5 \times 5^{\prime}(1.5 \times 1.5 \mathrm{~m})$ platform. The running surface of the ramp was 24 feet $(7.4 \mathrm{~m})$; the first 12 feet $(3.7 \mathrm{~m})$ were covered in packed snow while the rest was left bare (Fig. 1). The ramp had a plastic decking surface that had an abrasive top for improved traction, and slats that allowed snow to fall through. The ramp was modified with wood boards underneath so that snow would accumulate on top of the decking.

The flat surface condition was the same width and length as the incline condition, however, there were no handrails installed. The path upon which the participant was to travel was outlined on the concrete floor using chalk. The first $3.66 \mathrm{~m}$ (12 feet) of the surface was covered in packed snow, and the remaining $3.66 \mathrm{~m}$ of the surface was left bare. The surface underneath the packed snow, as well as the wheeling surface for the bare condition was smooth concrete (Fig. 1). 


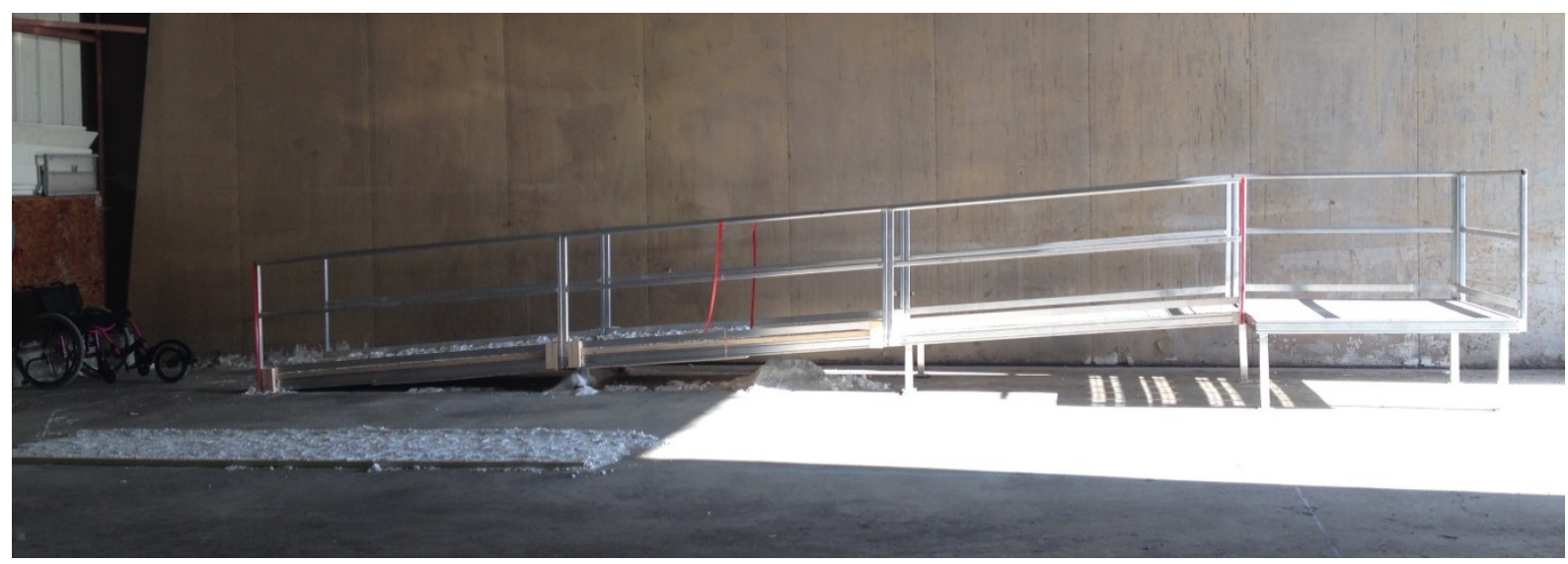

Figure 1 Inclined (back) and flat (front) experimental setup

\subsubsection{Method for Creating Packed Snow}

Based on the method described by LeMaire et al (2010), the following method was used to create the packed snow condition: Wooden blocks that were $4 \mathrm{~cm}$ tall were installed on the outside edges of the running surfaces of both the ramp and flat floor (Fig. 2A). Loose snow from outdoors was loosely deposited onto the flat and inclined surfaces between the blocks. The snow was evened out over the top of the $4 \mathrm{~cm}$ blocks using a flat board (Fig. 2B). Once the loosely deposited snow was evenly distributed at a $4 \mathrm{~cm}$ depth it was then packed down by foot until it resembled sidewalk conditions, approximately $1.5 \mathrm{~cm}$ depth throughout (Fig. 2C). The snow was re-packed by foot after every trial to eliminate tire tracks. 

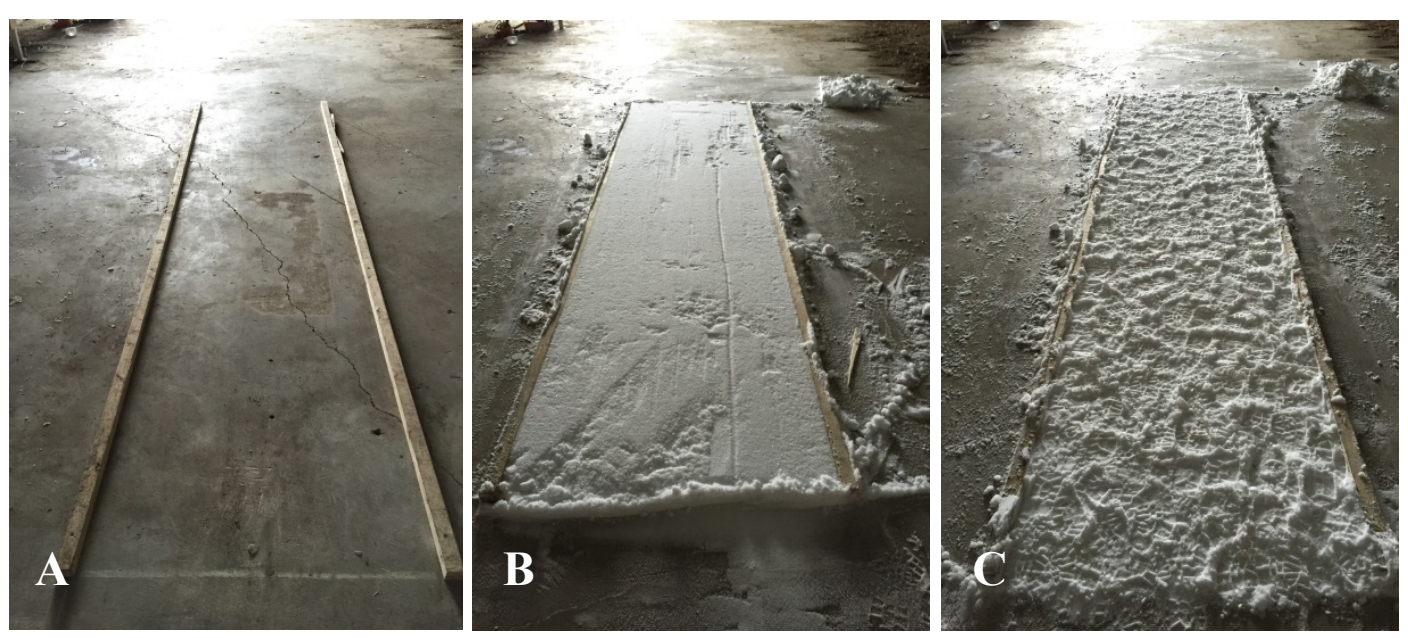

Figure 2 Method for packing snow. A) Bare B) Loosely packed snow C) Snow packed by foot

\subsubsection{Caster Types}

Four commercial caster types were tested in this study: solid, pneumatic, Freewheel, Wheel Blades. Solid casters are a common choice for wheelchair configurations as they are small, light, and very efficient to use on smooth indoor surfaces as the hardness of the material causes minimal rolling resistance. The solid casters used in this study were original components of the wheelchair used (Fig.3), and they were solid polyurethane casters with a diameter of 15.24 $\mathrm{cm}\left(6^{\prime \prime}\right)$ and width of $1.27 \mathrm{~cm}\left(0.5^{\prime \prime}\right)$.

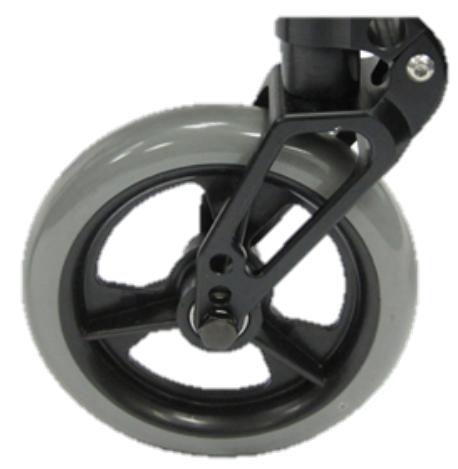

Figure 3 Solid caster type 
Pneumatic casters are another common component for wheelchair configurations (Fig.4). Pneumatic casters have many of the same properties as solid casters, however, they are usually softer and presumed to be better for rolling on rougher terrain. The pneumatic casters used in this study had a diameter of $15.24 \mathrm{~cm}(6 ")$ and a width of $3.18 \mathrm{~cm}(1.25 ")$ and were inflated to the recommended pressure of 36 psi for testing.

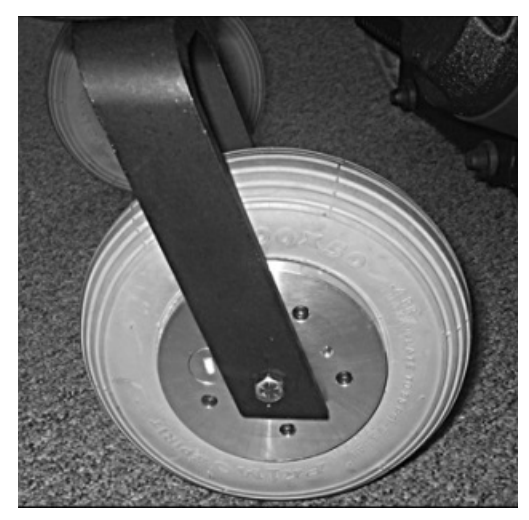

Figure 4 Pneumatic caster type

The Freewheel is a specialized tire, which is advertised as being compatible with all makes and models of manual wheelchairs (Fig.5). The Freewheel is a large single tire, which mounts to the wheelchair at the footplate: its large diameter allows the existing front casters to be lifted off of the ground. The Freewheel has a diameter of $31.75 \mathrm{~cm}(12.5$ ") and a tire width of $5.72 \mathrm{~cm}(2.25 ")$ and was inflated to the recommended pressure of $40 \mathrm{psi}$. 


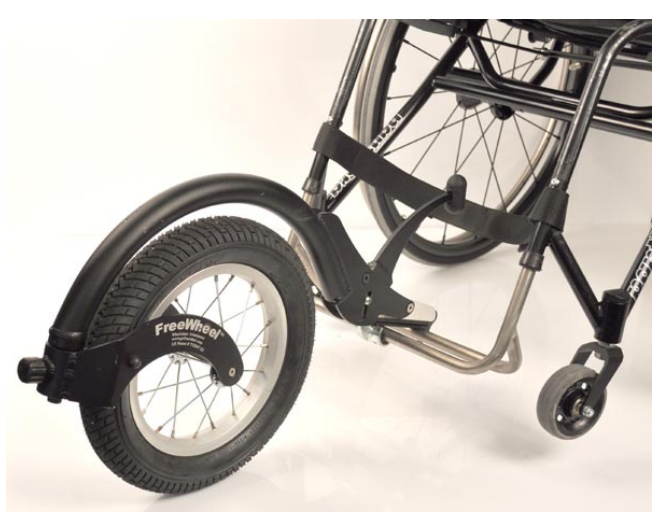

Figure 5 Freewheel caster type

The Wheel Blades are another specialized caster type, designed specifically for use in snow conditions (Fig.6). They are small adjustable skis that attach to the existing caster of a wheelchair. The Wheel Blades have a width of $11 \mathrm{~cm}(4.33$ ") and a length of $25.8 \mathrm{~cm}(10.16 ")$ (fig. 6). In this study, the skis were not used on the bare surface because the skis were designed to be used solely on the snow.

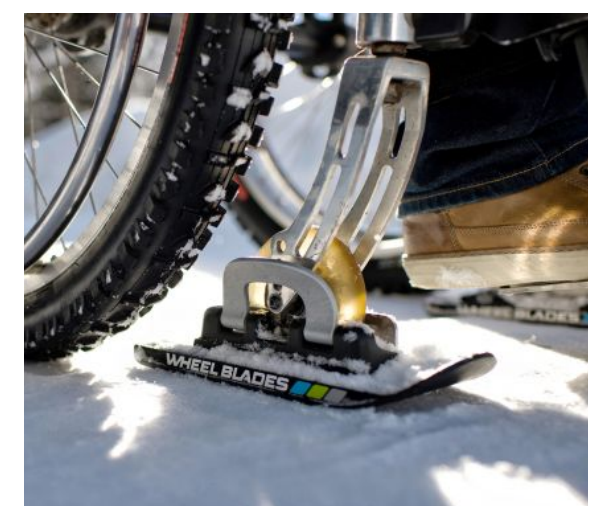

Figure 6 Wheel Blade caster type

\subsubsection{Description of Wheelchair}

The wheelchair used for the study was a lightweight rigid frame aluminum wheelchair Sunrise Medical Quickie GPV (Fig.7). It could be considered an athletic type chair, as it had a 
$12^{\circ}$ camber of the rear drive wheels and was configured in such a way that it had a high manoeuvrability, but a somewhat decreased stability. The wheelchair was equipped with antitipping bars to ensure the safety of the participants of the study. This wheelchair had a rigid footrest, which was able to accommodate the Freewheel attachment.

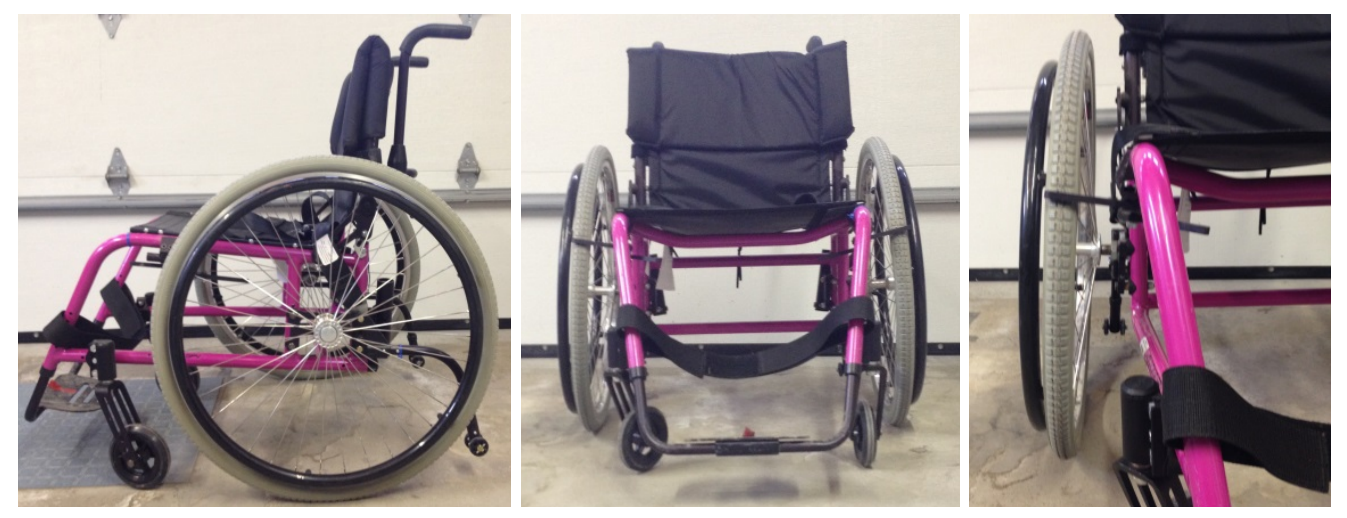

Figure 7 Sunrise Medical Quickie GPV manual wheelchair

\subsection{Experimental Phase 1 - Human Performance}

Phase one of the experiment was performed in the winter of 2015. The main goal of this first phase was to assess human performance while using the wheelchair under the different surface and caster conditions. Performance measures assessed were performance time for traveling $3.66 \mathrm{~m}$ (12 feet), number of strokes used to travel $3.66 \mathrm{~m}$ (12 feet), force transfer through the palms of the hands for $3.66 \mathrm{~m}$ of travel, and perceived physical exertion per trial. Two surface conditions were tested: bare wheeling surface, and packed snow. Two incline conditions were tested: flat, and 1:12 incline. Four caster conditions were tested: solid, pneumatic, FreeWheel, and Wheel Blades. Three replicates of each combination of surface, incline and caster condition were completed with a total of 11 human participants. 


\subsubsection{Background}

In section 1.1, the HAAT model of assistance technology design and the importance of considering the human element in assistive technology design was discussed. Focusing on human performance while using the four different caster technologies provides a unique perspective when determining the casters' effectiveness. While not assessing the performance of the technology for a particular client, we were able to choose measures that reflected how the general population might respond to using the different wheelchair caster types. In an attempt to standardize the testing environment, quantifiable measures of human performance were chosen. Performance time, stroke count, force transfer through the palms as well as the participants' perceived physical exertion were collected in this phase of the study. Heart rate was also collected to provide insight into the perceived exertion metric. Unfortunately, issues with collection resulted in the loss of the heart rate data, however, it is recommended to collect heart rate in future studies. Qualitative measures such as the participants' opinions of the effectiveness of the casters were not collected as research participants were not experienced wheelchair users and had very limited knowledge on the subject.

The methodology of the phase one study was similar to previous studies performed on wheelchair user performance. Snow surface preparation was similar to that done by Lemaire et al. (2010). Performance time and stroke count metrics had previously been used in studies performed by Marrow and Koontz (2005). Previously specialized instrumented wheels have been used to measure the force required to propel a wheelchair. Previously it was found by Morrow et al. (2010) that force sensing gloves and the commonly used instrumented "SMARTwheel" produced comparable results. A more cost effective force measurement strategy was implemented by using a force-sensing array placed on the palms of the participants' hands. 
Finally, while the modified Borg scale rating of perceived physical exertion has not been previously used in the context of wheelchair user performance, it is a measure which has been used in other contexts involving physical activity such as running and cycling (Purvis et al., 1981).

\subsubsection{Participant Procedure}

Eleven able-bodied participants (novice wheelchair users) were recruited to participate in the study. Participants were between the ages of 21-28 (mean 23.2), 7 were male and 4 were female. The original study was planned to have 15 participants, however, due to warm weather conditions testing was ceased before being able to test all participants. The University of Manitoba's Education and Nursing Research Ethics Board approved the study, and all participants signed forms of informed consent before beginning the study.

Participants were trained on using a wheelchair, first with a YouTube instructional video (Max-Mobility USA, 2012), then with verbal advice from the investigator. Participants were given time to practice and to become comfortable using the wheelchair. Once the participants were comfortable using the wheelchair, trials began. One trial consisted of the participant traversing a $7.32 \mathrm{~m}$ ( 24 foot) distance, where the first $3.66 \mathrm{~m}$ (12 feet) were a snow-packed surface, and the final 3.66m (12 feet) were clear of snow. Trials occurred on both flat and inclined surfaces, and three replicates of each trial were performed. Testing was blocked by caster type, and trials were alternated between flat and inclined during testing. The order in which the casters were tested was completely randomized. Participants were instructed to proceed at a comfortable pace if they requested that information. In post processing, the data for snow and bare conditions were separated. 
Several precautions were taken to ensure the safety of the participants during the study. Participants were instructed on how to properly propel a manual wheelchair and were given time to practice with feedback from the investigator. The wheelchair was fitted with anti-tipping bars to prevent tips and falls from the chair. Warm gloves were provided to all the participants for consistent grip, and participants were encouraged to wear warm, weather appropriate clothing as the duration of the study lasted approximately $2 \mathrm{~h}$.

\subsubsection{Instrumentation \& Data Collection}

Performance measures collected included the total performance time per trial, number of propulsive movements, Borg Scale rating of perceived physical exertion, and force transfer through the palms of the hands (impulse).

All trials were video recorded from a position perpendicular to the line of motion. Videos were used to determine the time to complete each portion of the individual trials (snow pack/bare portions) using the stopwatch function in the Kinovea video analysis software (Version 0.8.15, 2015). Video review was also used in counting the number of propulsive movements that were made in each portion of the trial, as well as recording some events such as instances as becoming stuck and handrail usage during the incline condition. Propulsive movements were defined as a common wheelchair stroke using the hand rim on the wheel, or as a pulling motion using the handrails on the ramp. Amount of propulsive movements used over a set distance is an indicator of the mechanical efficiency of the system (wheelchair's interaction with the environment); fewer propulsive movements indicate better mechanical efficiency.

A rating of perceived exertion (RPE), despite being a subjective measure, provides useful information on how the user feels after using the technology, and how they perceived the 
effectiveness of the technology. Participants were trained on how to use the modified Borg scale (Borg, 1998) before beginning the study. Immediately after every trial participants would rate their perceived physical exertion for that trial on a scale from 1-10. This measure gives insight into how much effort is required of using each caster type.

Small flexible force sensors (Delsys - Trigno ${ }^{\mathrm{TM}} \mathrm{Lab}$ ) were adhered to the palms of the participants' hands in 4 locations that made contact with the hand rim of the wheelchair (Fig. 8). Data were collected separately for each trial; snow-pack and bare values were separated using the performance time. Force was measured through electrical resistance, which has a linear relationship with the applied force. After collection, Force-Time data were transformed into a measure of impulse (change in linear momentum) through calculating the area under the forcetime curve.

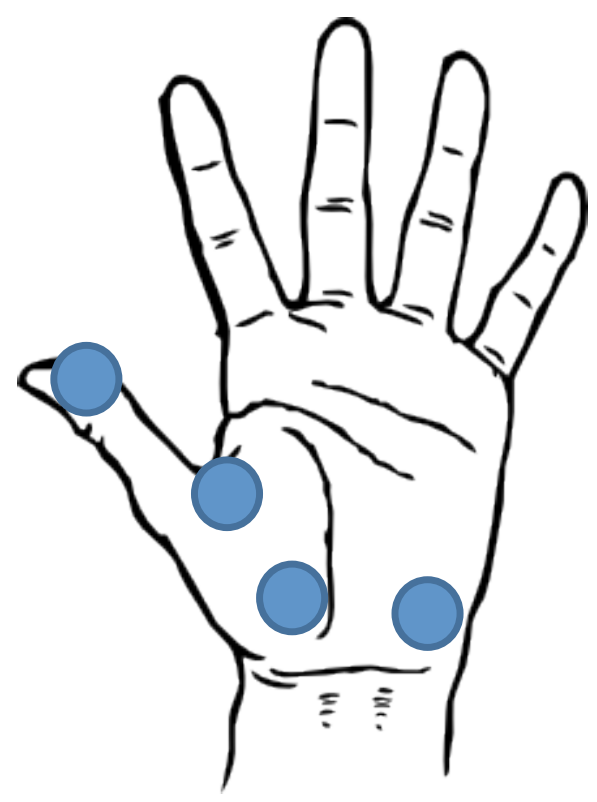

Figure 8 Force sensor placements on the palm of the hand 


\subsection{Experimental Phase 2 - Mechanical Performance}

Phase two of the experiment was performed in the winter of 2016. The main goal of this second phase of experimentation was to assess the mechanical performance of the wheelchair under different surface and caster conditions. Performance measures assessed were static resistance to movement, kinetic resistance to movement, and caster penetration depth into the packed snow. Only the packed snow surface type was used, however, bare surface and solid caster type was used as a baseline condition. Two incline conditions were tested: flat and 1:12 incline. Four caster conditions were tested: solid, pneumatic, FreeWheel, and Wheel Blades. Three replicates of each combination of incline and caster condition were taken, as well as a baseline. Participants were not used for this phase of the study; rather a winch equipped with a load cell was used to pull a weighted wheelchair through the snow-pack.

\subsubsection{Background}

Previously in section 1.1 the importance of an assistive technology's interaction with its environment was discussed. The context in which an assistive technology is used must be considered when designing the interfaces between the mobility device and the environment. In this case the interaction being studied was the wheelchair caster interfacing with packed snow. The performance measures that were considered were static and kinetic rolling resistance, as well as caster penetration into the snow-pack.

The method of measuring rolling resistance in this experiment was different from other methods used. Previous studies have used a technique where the wheelchair is released from an incline and resistance to rolling can be calculated by the distance that the wheelchair has traveled over the surface (Sauret, 2014). Due to the caster penetrating into the snow pack, the wheelchair would simply tip or become stuck once it reached the snow. A new method of measuring static 
and kinetic rolling resistance was developed in this study through the use of a load cell in tension and towing the wheelchair using a winch.

Snow behaves unlike other rolling surfaces that have been previously studied in the wheelchair literature such as concrete, carpet, or bricks. The viscoelastic properties of packed snow will affect rolling resistance in the way that it deforms under the weight and movement of the wheelchair. It was hypothesized that if a caster penetrated deeply into the snow pack, it would have an increased rolling resistance due to the fact that it would compress the snow until it reached a yielding point.

\subsubsection{Trials}

This portion of the study was completed using the wheelchair loaded with $80 \mathrm{~kg}$, the approximate weight of an average Canadian male. The wheelchair was pulled using a $2000 \mathrm{lb}$ ATV winch (Trakker KT2000-1) powered by a $12 \mathrm{~V}$ battery. Set at a speed of $0.25 \mathrm{~m} / \mathrm{s}$, the wheelchair traveled at approximately the average speed of the participants from the first phase of the study. The wheelchair was connected to the winch using inelastic nylon rope tied to the solid frame at the same height as the axles of the rear wheels. The winch pulled the chair parallel to the surface plane so as to not create a perpendicular force component.

A baseline condition was initially collected, which was solid casters on a bare surface for both flat and inclined conditions. Following baseline condition, all four caster types were tested on both flat snow-packed surface as well as the inclined snow-packed surface. Three replicates of each condition were collected. 


\subsubsection{Instrumentation \& Data Collection}

Resistance to movement was collected using a load cell (Interface) in tension paired with a data acquisition system (Agilent 34907A) running Agilent software. Collecting at 5Hz, static and kinetic resistance to movement was measured. Post processing of the data revealed a force spike followed by a lower plateau of forces. The force spike was identified as the static resistance, and the lower plateau was identified as the kinetic resistance and the forces collected were averaged over a period of $10 \mathrm{~s}$.

Caster penetration into the snow pack was measured using callipers. Depth of the snow at the center of the rut created by the caster was measured at three points along the distance that the wheelchair was pulled. Penetration was calculated by subtracting the depth of adjacent undisturbed snow from the depth of the snow at the center of the rut created by the caster wheel. Only one individual collected the penetration data; accuracy could have been increased by employing two or more individuals to collect this measure to increase reliability. 


\subsection{Results}

In the following sections results of both the first and second phase experiments will be presented. Observations noted during data collection will be presented below and included in the discussion. Initially the pneumatic, solid, and freewheel casters were tested in the bare surface condition and were not found to have any significant difference in all the performance measures of the caster types. Following these results, the solid caster type on a bare surface was used as a baseline condition to compare to the four caster types on a snow-packed surface.

\subsection{Phase 1 Results}

Statistical analysis was done using SPSS software. A within participants design was chosen using a repeated measures ANOVA followed by pair-wise comparisons in the cases where significant effects were found. The following graphs are labeled as such: Baseline Condition (BL), Solid Casters (SO), Pneumatic Casters (PN), FreeWheel (FW), and Wheel Blades (WB). It was hypothesized that the packed-snow condition, as well as the inclined condition would have a negative effect on the performance of the wheelchair. It was also speculated that the specialized casters (FreeWheel and Wheel Blades) would perform better than the traditionally prescribed casters due to their advertised claims.

The results confirmed the expectation that there was in fact decreased performance during the snow-packed trials, and the inclined trials. Unfortunately, the results also conclude that the specialized casters are not performing as expected on the packed-snow conditions for all the performance measures. Of the four caster types, only the FreeWheel had significantly improved performance, and at that, only in the areas of performance time and perceived exertion. The Wheel Blade caster type did not perform differently from the traditional caster types in any of the performance measures. 


\subsubsection{Performance Time}

Performance time on an incline (1:12) was significantly longer than on a flat surface.

Mean performance time on an incline was $19.7 \mathrm{~s}$, whereas on flat surface the mean performance time was $6.7 \mathrm{~s} F(1,10), \mathrm{P}<0.05$. This result was expected as aforementioned studies have identified similar relationship between angle of incline and performance time.

Caster type was found to be a main effect where $\mathrm{F}(4,7), \mathrm{P}<0.05$. Post-hoc pairwise comparison analysis was done using Tukey's HSD and it was found that the baseline condition (solid casters on bare surface) had a significantly shorter performance time compared to all caster types on a snow-packed surface in both flat and inclined conditions, $\mathrm{P}<0.05$. Of the caster types being used on a snow packed surface, the FreeWheel caster type had significantly shorter performance times in both the incline and flat conditions, $\mathrm{P}<0.05$ (Fig. 9).

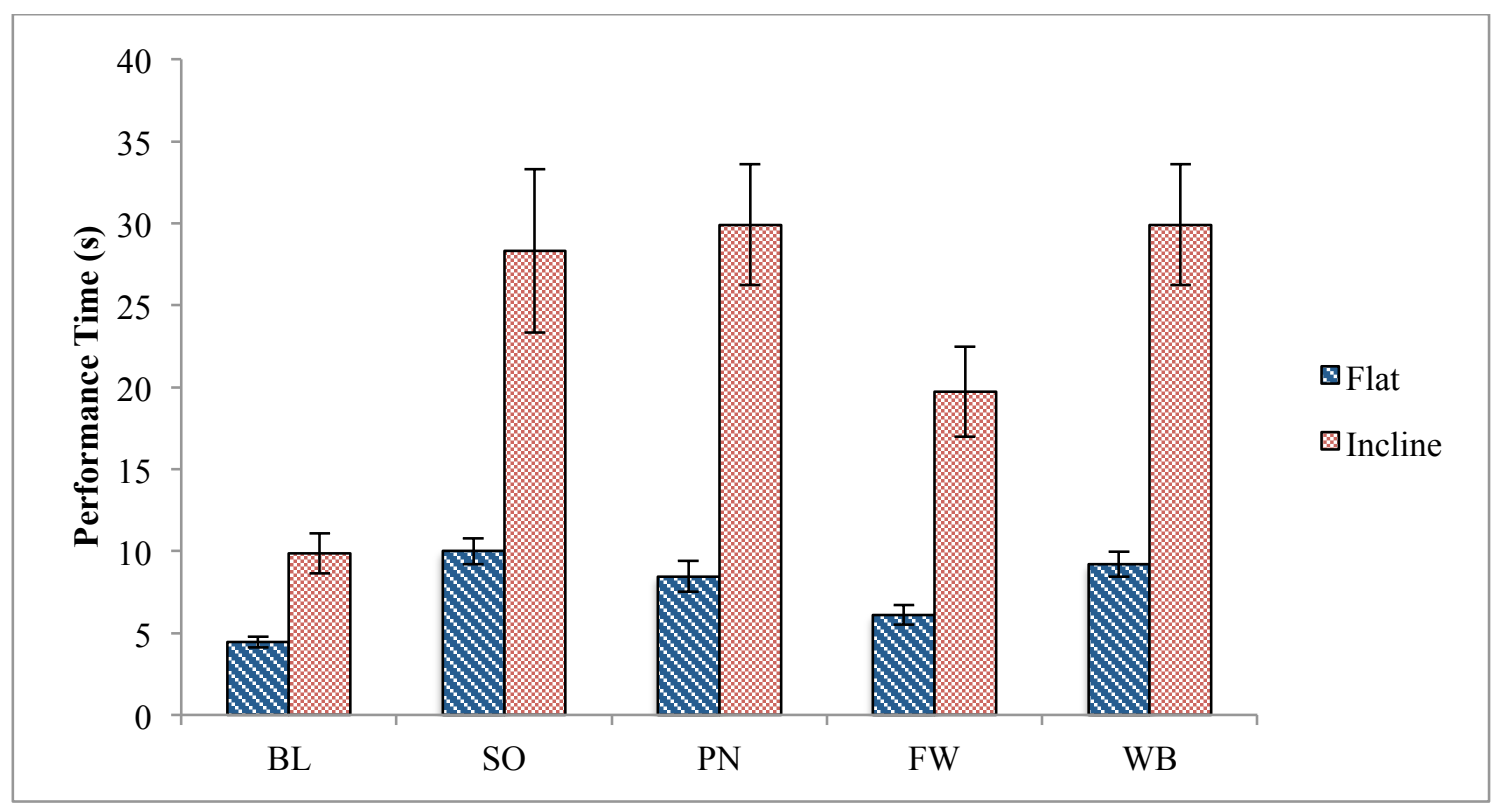

Figure 9 Performance time. The baseline condition was found to be significantly smaller than the casters used on packed snow in both the flat and incline condition. Of the casters used on the snow-packed surface, it was found that the FreeWheel caster had a significantly shorter performance time compared to the other three caster types. 


\subsubsection{Perceived Physical exertion}

A repeated measures ANOVA of the RPE data suggests that caster type did in fact have an effect on the wheelchair users' perceived physical exertion (Fig.10). Pairwise comparisons revealed that the FreeWheel caster had a significantly lower RPE than the three other casters in both flat and incline conditions $(\mathrm{P}<0.05)$. This result indicated that the FreeWheel caster was perceived as requiring the least physical exertion to use in the packed snow conditions, with an average of 1.4 out of a possible 10 compared to the other caster types averaging 2.8 out of 10 .

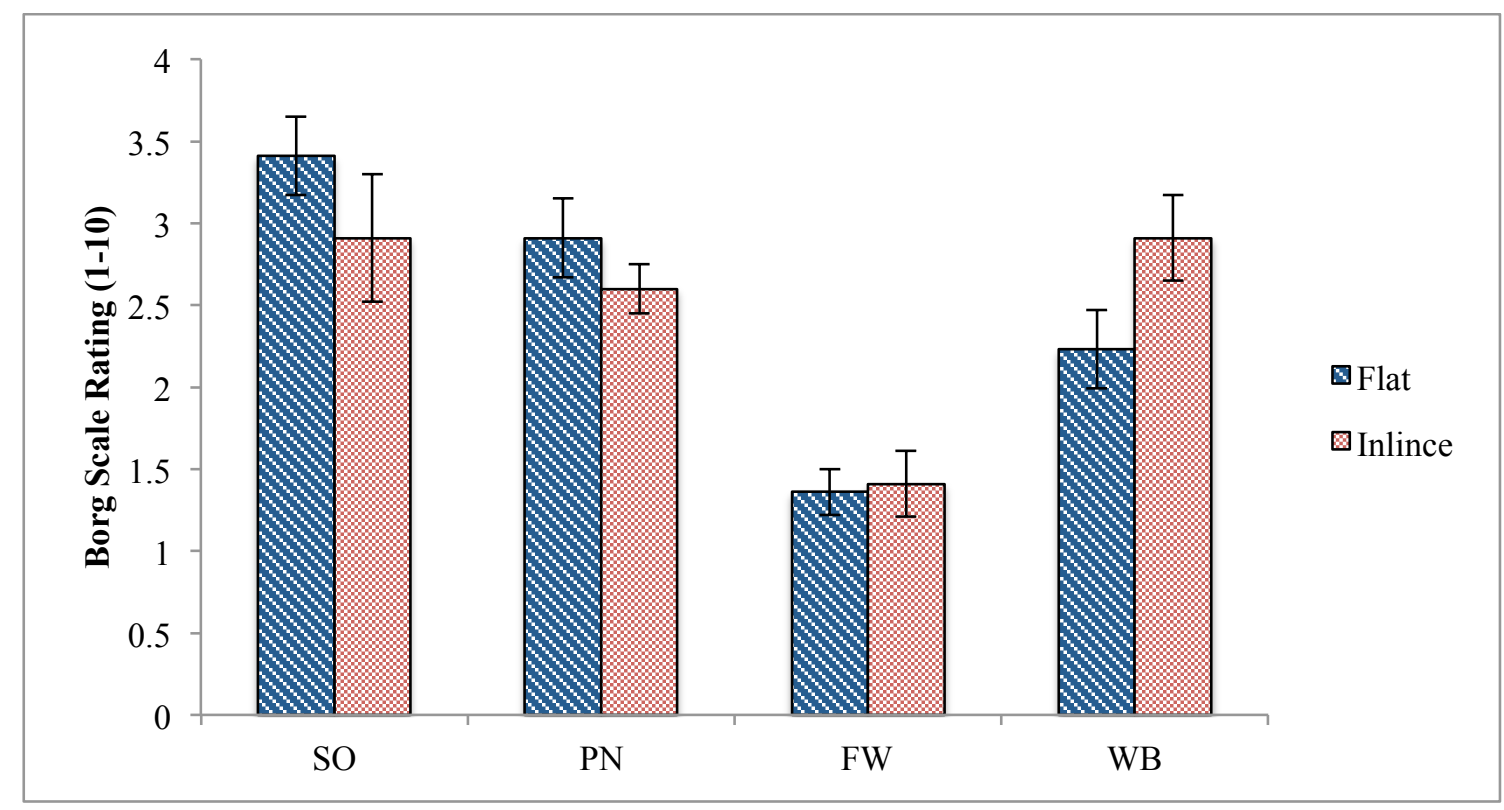

Figure 10 Borg's rating of perceived physical exertion. The FreeWheel caster was perceived as requiring the least physical exertion in both the flat and incline conditions $(\mathrm{P}<0.05)$.

Incline and caster-incline interaction did not have an effect on perceived physical exertion, with average RPE values of 2.5 for both flat and inclined conditions. This result was unexpected, as intuitively climbing an incline should require more physical exertion than 
propelling oneself over a level surface. Possible explanations for the result could be due to the experimental conditions: For the incline condition there was a handrail for safety and was available for the participants to use in case of becoming stuck, whereas on the flat surface condition that option was not available. Another explanation is that the packed snow obstacle was so difficult to overcome that the effect of the incline became negligible when considering perceived physical exertion.

\subsubsection{Impulse}

Impulse required on an incline (1:12) was significantly larger than on a flat surface. Mean impulse value on an incline was 153.55 , whereas on flat surface the mean impulse value was 23.27 $\mathrm{F}(1,10), \mathrm{P}<0.05$. Again, this result was expected as previous studies have identified a relationship between angle of incline and forces required of a wheelchair user.

Caster type was found to be a main effect where $F(4,7), P<0.05$. Post-hoc pairwise comparison analysis was done using Tukey's HSD and it was found that the baseline condition (solid casters on bare surface) had a significantly smaller impulse values compared to all caster types on a snow-packed surface in both flat and inclined conditions $(\mathrm{P}<0.05)$. Of the caster types being used on a snow packed surface, the FreeWheel caster type had significantly smaller impulse values than the solid caster type, but was not found to perform better than the pneumatic or Wheel Blade caster types (Fig. 11). 


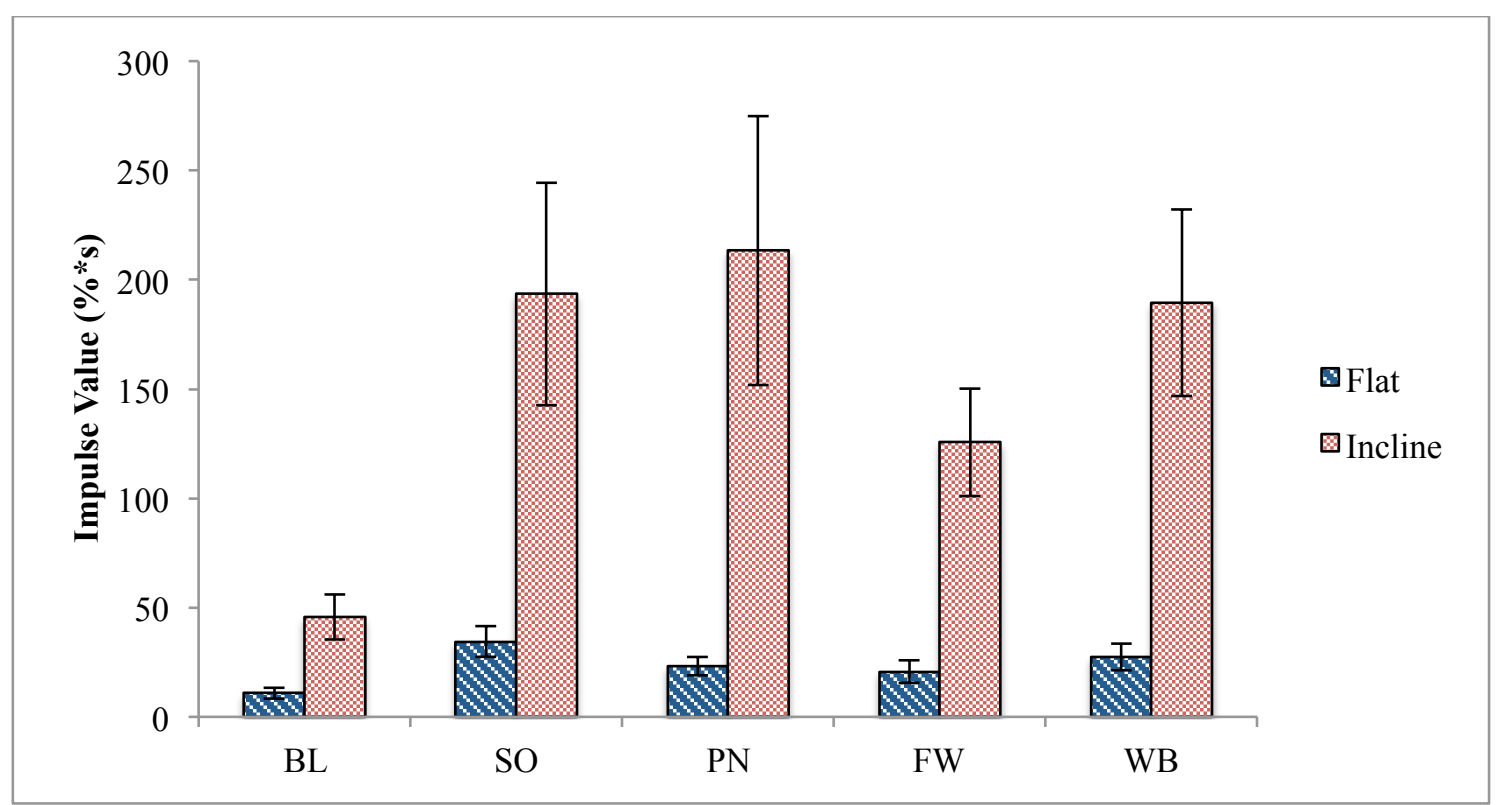

Figure 11 Impulse. The baseline condition was found to be significantly smaller than the casters used on packed snow in both the flat and incline condition. Of the casters used on the snow-packed surface, it was found that the FreeWheel caster had a significantly smaller impulse value than the solid casters, however it was not different from the pneumatic or Wheel Blade caster types.

\subsubsection{Propulsions}

Number of propulsive movements required on an incline (1:12) was significantly larger than on a flat surface. The mean number of propulsive movements on an incline was 6.6, whereas on flat surface the mean number of propulsive movements was $11.2 \mathrm{~F}(1,10), \mathrm{P}<0.05$. Again, this result was expected as previous studies have identified a relationship between angle of incline and effort required of a wheelchair user.

Caster type was found to be a main effect where $\mathrm{F}(4,7), \mathrm{P}<0.05$. Post-hoc pairwise comparison analysis was done using Tukey's HSD and it was found that the baseline condition (solid casters on bare surface) required significantly few propulsive movements compared to all caster types on a snow-packed surface in both flat and inclined conditions $(\mathrm{P}<0.05)$. Of the caster 
types being used on a snow packed surface, the FreeWheel caster type had significantly smaller impulse values than the three other caster types (Fig. 12).

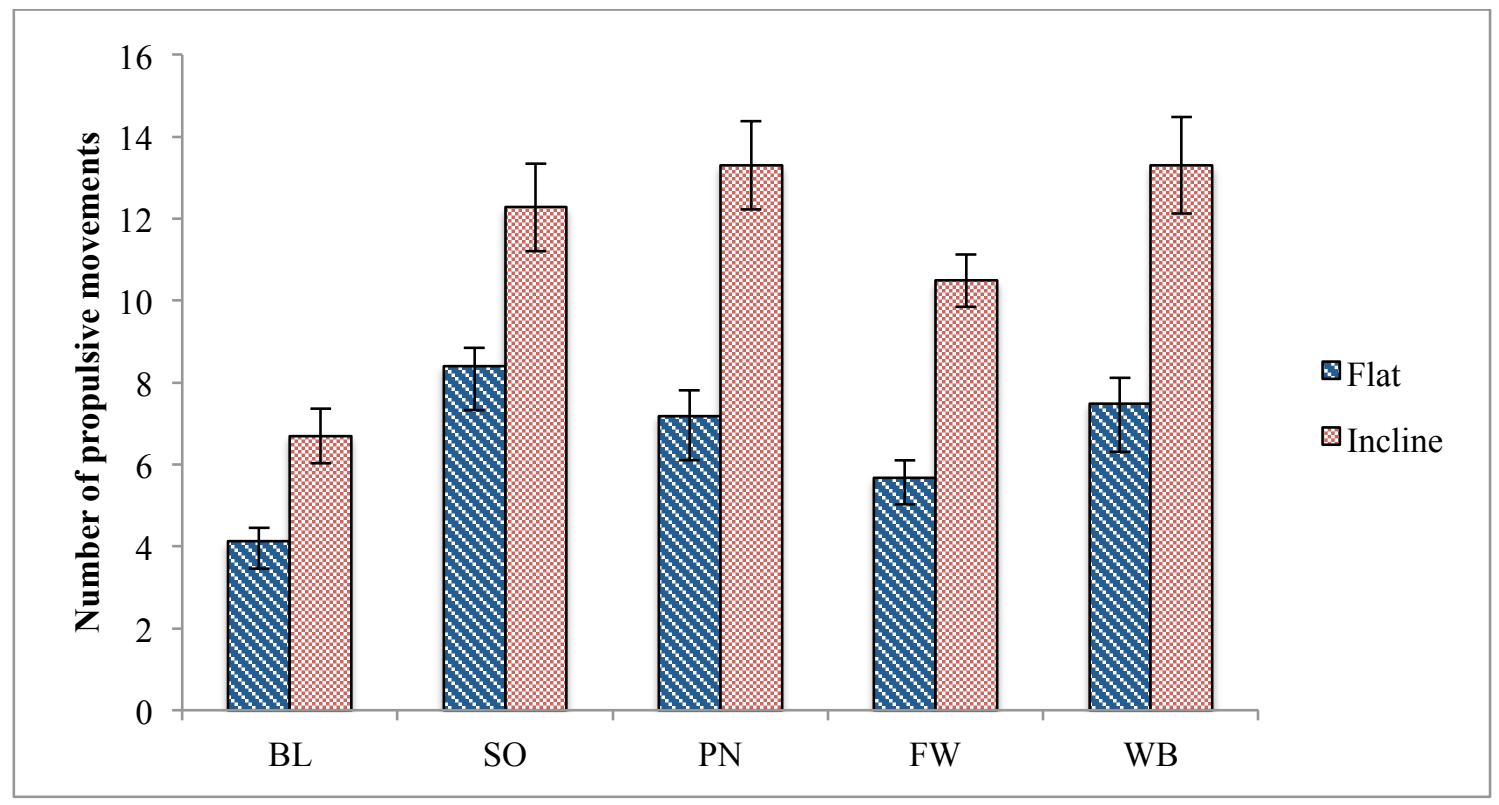

Figure 12 Propulsive movements. The baseline condition was found to be significantly smaller than the casters used on packed snow in both the flat and incline condition. Of the casters used on the snow-packed surface, it was found that the FreeWheel caster required significantly less propulsive movements than the three other caster types.

\subsubsection{Observations}

All participants quickly learned to balance weight on the back wheels of the wheelchair, but would often overshoot and fall back on the anti-tip bars. Quantifying unsafe maneuvering would be an asset in a study such as this one, as future caster designs should aim to eliminate risky maneuvering. Backwards tipping also made it difficult to compare the caster types, as they were not always making contact with the surface. Most participants had difficulty overcoming the entrance to the ramp, and if they were to use the hand rims of the wheelchair to propel themselves they would spin their wheels at the entrance. Many participants would slide or tip backwards once they surpassed the entrance of the ramp. Most participants opted to use the handrails to pull themselves up the initial entrance of the ramp, and would eventually revert to 
propelling with the hand rims. Finally, the Wheel Blade caster type showed very few instances of becoming stuck in the snow-pack. However, in the incline condition, it was observed that the Wheel Blade caster would result in backwards slipping between propulsive movements.

\subsection{Phase 2 Results}

Statistical analysis was done using SPSS software. A repeated measures ANOVA was performed for each performance measure, and followed by pair-wise comparisons in the cases where a main effect was found. The following graphs are labeled as such: Baseline (BL), Solid Casters (SO), Pneumatic Casters (PN), FreeWheel (FW), and Wheel Blades (WB). It was hypothesized that there would be a relationship between penetration and resistance.

\subsubsection{Static Resistance}

Analysis of variance revealed that there was a significant difference in static resistance between flat and inclined conditions (Fig 13). In the flat condition the static resistance of the wheelchair for all caster conditions were similar, including the baseline condition (Mean $=110.7$ $\mathrm{N})$, although the baseline condition appeared to be considerably lower than the snow-packed condition with an average of $29.3 \mathrm{~N}$. However, for the incline condition the static resistance for the baseline was significantly less than all the caster types that had to move through the snow pack. The flat baseline condition was an average $179.5 \mathrm{~N}$, whereas the other caster types on snow-pack was an average $266.2 \mathrm{~N}$. 


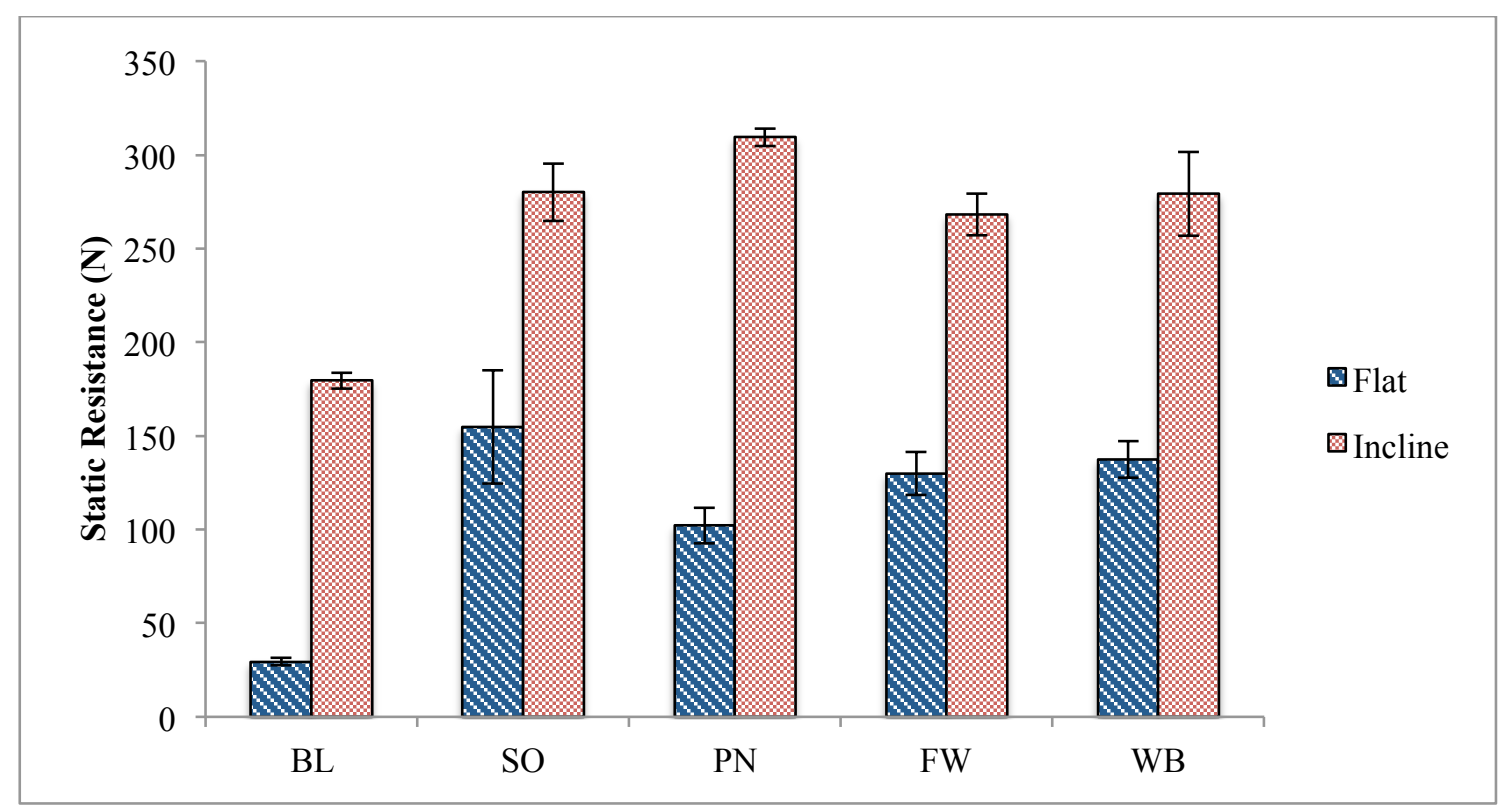

Figure 13 Static resistance to movement. There was found to be a significant difference between the flat and inclined conditions. In the incline condition the baseline experienced significantly lower static resistance than the other caster types.

\subsubsection{Kinetic Resistance}

Analysis of variance reveals that there was a significant difference in kinetic resistance between flat and inclined conditions, similar to the results for static resistance (Fig. 14). For the inclined condition, solid casters were found to be associated with significantly higher kinetic resistance than the other caster types $($ Mean $=217.7 \mathrm{~N})$, whereas the baseline caster condition had significantly lower kinetic resistance than all other caster types $(\mathrm{Mean}=136.0 \mathrm{~N})$. For the flat condition there was no significant difference between caster conditions, however they follow the same trend, where the baseline condition has a smaller kinetic resistance (Mean $=72.6 \mathrm{~N}$ ) and the solid casters had a larger kinetic resistance $($ Mean $=142.9 \mathrm{~N})$ than the other three caster types. 


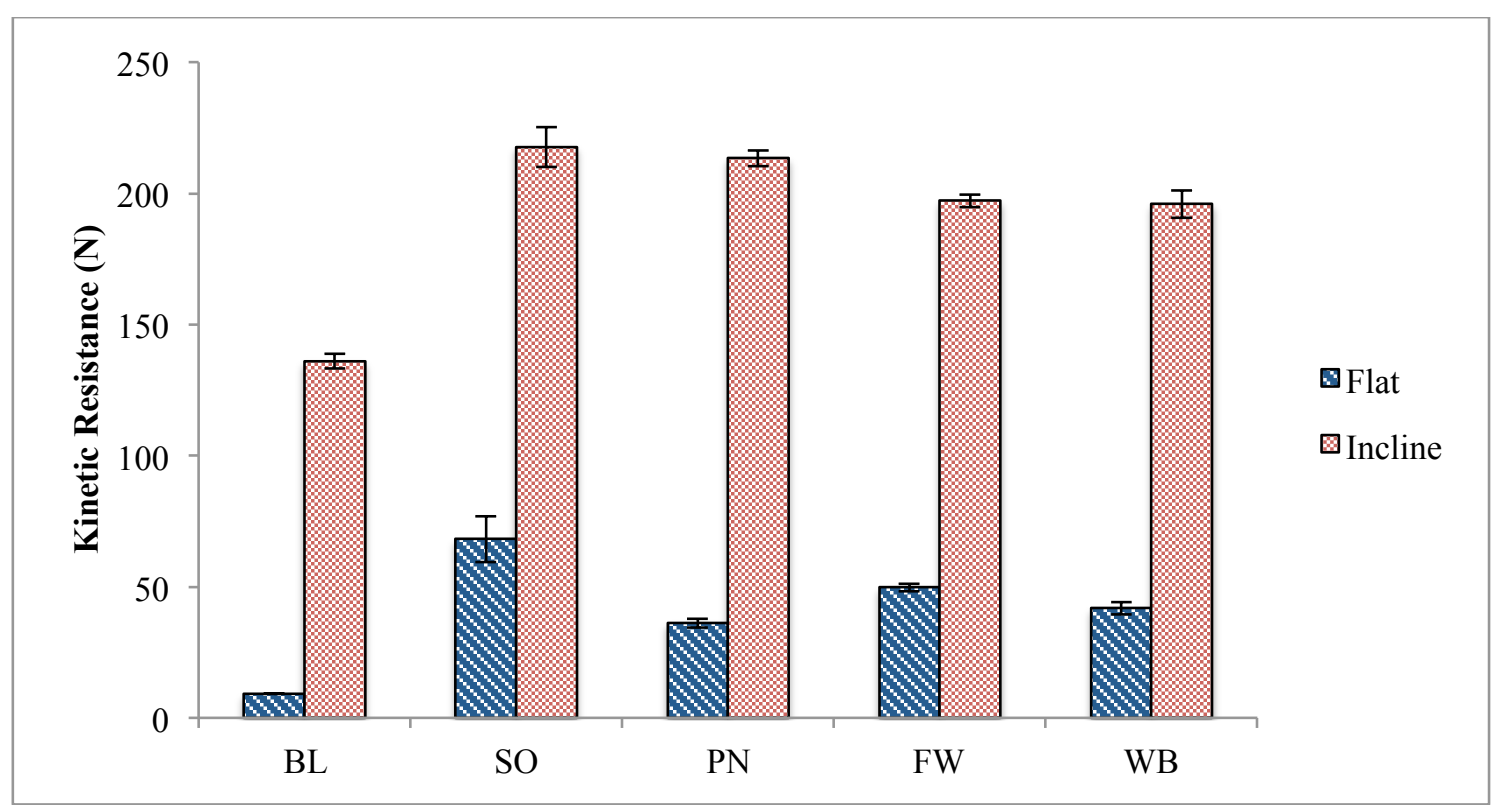

Figure 14 Kinetic resistance to movement. There was found to be a significant difference between the flat and inclined conditions. In the incline condition the baseline condition experienced significantly lower kinetic resistance than the other caster types on a snow packed surface. The solid casters experienced significantly larger kinetic resistance than the other caster types being used on the snow packed surface.

\subsubsection{Penetration}

Unlike the measures of resistance, caster penetration into the snow-pack did not have a relationship with the incline condition, and was not found to be significantly different between the flat and incline conditions (Fig.15). It was found that the FreeWheel caster, and the Wheel blades casters were statistically similar $(\mathrm{P}>0.05)$ to the baseline condition on a flat surface, together their average penetration was $1.3 \mathrm{~mm}$. The solid and pneumatic caster types were found to have a significantly larger penetration into the snow-pack for both flat and incline conditions $($ Mean $=11.7 \mathrm{~mm})$ 


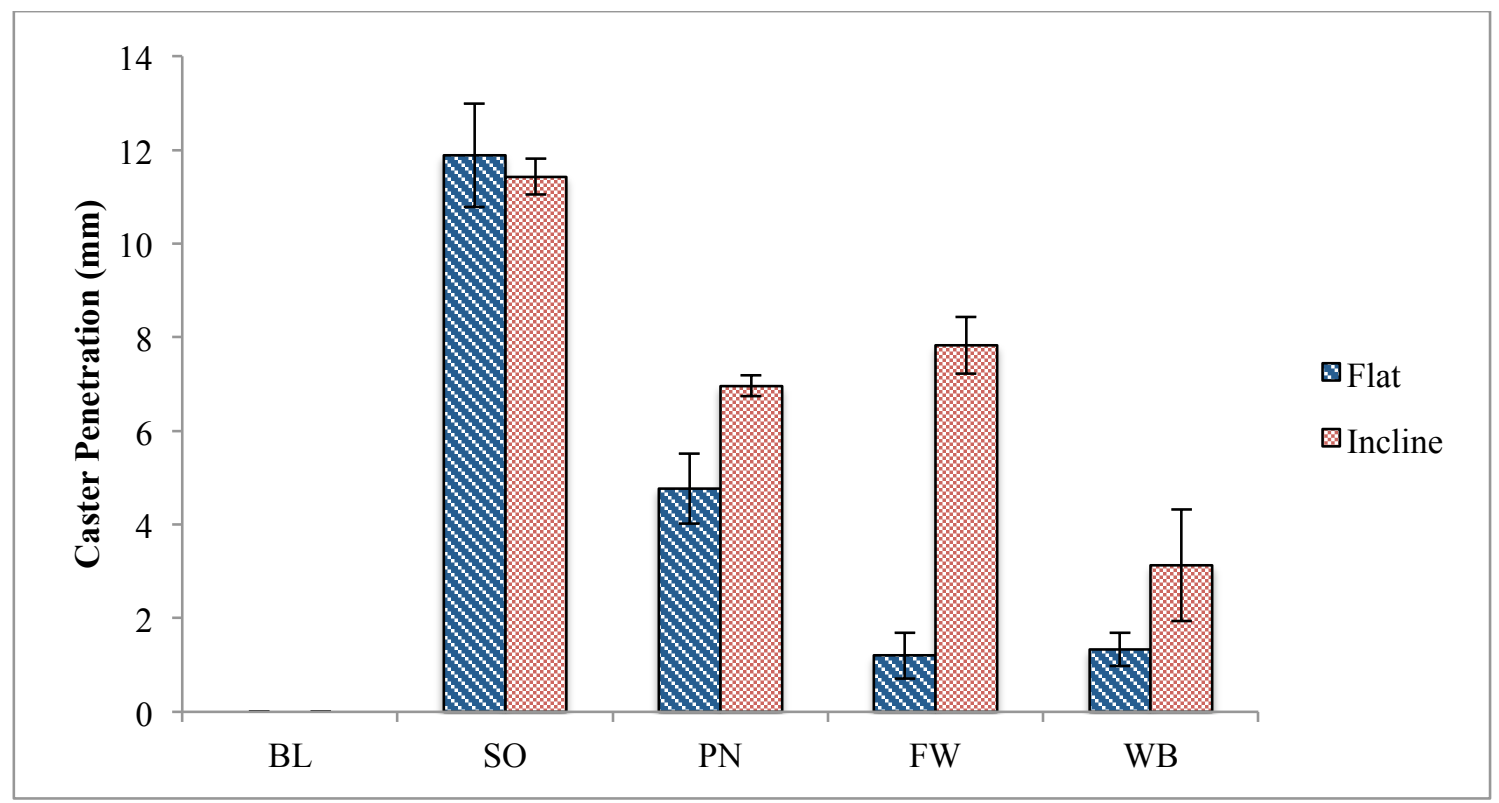

Figure 15 Caster penetration into snow-pack. No significant difference was found between flat and inclined conditions. Solid casters were found to have a significantly larger penetration in both flat and inclined condition. In the flat condition both the FreeWheel and the WheelBlades had a penetration value statistically similar to the baseline condition.

\subsubsection{Observations}

While pulling the wheelchair with the winch, it was observed that the wheelchair moved in jerky and erratic movements while traveling through the snow-pack. Despite being pulled straight at a constant rate, the wheelchair would not maintain a straight path; it would jerk in one direction, and then correct itself in the next movement. The erratic movements were most pronounced for the solid and pneumatic caster types, whereas they were more subdued for the FreeWheel and Wheel Blade caster types. This behaviour was not observed during the baseline trials, where the wheelchair was pulled along bare concrete or bare ramp decking; the movement of the wheelchair during the baseline trials was smooth and straight. The phenomena of erratic movements of the wheelchair could be due to the viscoelastic properties of compact snow. The profile of the caster created compression forces in the snow, which would eventually yield and allow the movement of the wheelchair. This phenomenon could explain why individuals who use 
wheelchairs in packed snow find it difficult to steer; the compacted snow under the casters is likely to yield at different instances, forcing the chair to turn unexpectedly.

Observing the data collected by the load cell confirmed that the forces matched the erratic movement of the chair. The force curve appeared as a sinusoidal wave, where the peak could be interpreted as the point where the snow yielded to the movement of the chair. The erratic movement phenomenon could have a relationship with caster penetration, as the casters that exhibited this behaviour were the ones that had a deeper penetration into the snow pack.

\subsection{Summary of Results}

The phase one experiment focused on assessing human performance measures for each caster type that was used. If was found that the presence of a packed-snow surface had a negative impact on human performance measures compared to bare surfaces. Also, the presence of an incline resulted in a negative impact on human performance measures. It was determined that the FreeWheel caster type performed better than the other caster types in performance time, and in a lower rating of perceived exertion while on the packed snow surface type, however it was not as effective as though there was no snow at all. While there were no statistically significant results indicating that the FreeWheel required fewer propulsive movements to complete the trial distance, visual analysis of the data suggests it tended to be less than the other caster types. The results for impulse indicated that no caster type performed differently than the others. During the trials it was observed that the participants were able to better control the movements of the FreeWheel as compared to the other caster types. It was also observed that the Wheel Blade casters were subject to backwards slipping while being used on an incline. 


\begin{tabular}{|l|c|c|c|c|c|}
\hline & $\begin{array}{c}\text { Performance } \\
\text { Time }\end{array}$ & RPE & Impulse & Stroke Count & Observations \\
\hline Solid & & & & & \\
\hline Pneumatic & & & & & \\
\hline FreeWheel & $\boldsymbol{V}^{*}$ & $\boldsymbol{V}^{*}$ & $\boldsymbol{V}$ & & $\checkmark$ \\
\hline Wheel Blade & & & & & \\
\hline
\end{tabular}

Figure 16 Summary of phase 1 results. Check marks indicate the caster type that had the best performance based on results and observations; an asterisk indicates that the result of the study was statically significant in either the flat of inclined condition.

The phase two experiment focused on assessing mechanical performance measures of the wheelchair for each caster type that was used. It was found that the presence of a packed-snow surface had a negative impact on the wheelchair's resistance to movement compared to the baseline condition. Also, the presence of an incline resulted in an increased rolling resistance for all caster types. Both the FreeWheel and Wheel Blade caster types had very minimal penetration into the snow-pack such that it was comparable to being on a bare surface, however no relationship between rolling resistance and penetration was found. While the results were not statistically significant, the pneumatic caster type had a lower mean kinetic resistance compared to the other caster types, and the Wheel Blades had a lower mean static resistance compared to the other caster types. During the trials it was observed that the FreeWheel caster type, as well as the Wheel Blades were able to maintain a straighter path with less erratic movements compared to the solid and pneumatic caster types.

\begin{tabular}{|l|c|c|c|c|}
\hline & $\begin{array}{c}\text { Static } \\
\text { Resistance }\end{array}$ & $\begin{array}{c}\text { Kinetic } \\
\text { Resistance }\end{array}$ & Penetration & Observations \\
\hline Solid & & & & \\
\hline Pneumatic & & $\checkmark$ & & $\checkmark$ \\
\hline FreeWheel & & $\checkmark$ & $\boldsymbol{V}^{*}$ & \\
\hline $\begin{array}{l}\text { Wheel } \\
\text { Blade }\end{array}$ & & $\checkmark$ & $\boldsymbol{V}^{*}$ & $\boldsymbol{V}$ \\
\hline
\end{tabular}

Figure 17 Summary of phase 2 results. Check marks indicate the caster type that had the best performance based on results and observations; an asterisk indicates that the result of the study was statically significant. 


\subsection{Discussion}

The following section will discuss the results and interactions of both phases of the study with regards to caster performance. It will also examine the success of the methodology used to determine the overall success of the study performed. Finally, limitations of this study, and future directions of study will be discussed.

\subsection{Consequences of caster design}

The following sections will examine and discuss each caster design individually with regards to how it may affect the wheelchair's performance results from both phases on packedsnow surfaces. It will also speculate as to the appropriateness for use within the context of everyday use.

\subsubsection{Solid Casters}

The solid polyurethane casters had the smallest wheel diameter as well as the smallest caster width, meaning that it has the smallest contact area when wheeling on ideal surfaces such as concrete or hardwood flooring. The small contact area of solid casters usually results in low rolling resistance and increased manoeuvrability, which makes it an ideal option when indoor flooring is the wheeling surface being used. However when considering packed snow, a small contact area results in a poor distribution of weight, leading to increased caster penetration into the wheeling surface. The increased caster penetration likely led to increased kinetic rolling resistance, as well as overall poor performance in the other measures tested. It is believed that the erratic movement of the chair in phase two of the study was likely related to the higher caster penetration. 


\subsubsection{Pneumatic Casters}

The pneumatic casters had a slightly larger diameter and width compared to the solid casters used in the study. In addition to having a larger contact area with the wheeling surface, it is also worth noting that the pneumatic casters were of a softer material type, meaning that the inflated rubber casters should be more capable of conforming to the shape of the wheeling surface to lessen shocks and increase contact area. Despite having similar geometric qualities with the solid casters, the pneumatic casters performed much better in the area of penetration depth, as well as slightly improved performance over the solid casters in the measures of kinetic resistance, RPE, and performance time. The similar shape and design to the solid casters suggests that the pneumatic casters would likely be appropriate for use on conventional wheeling surfaces without causing strain on the wheelchair user.

\subsubsection{FreeWheel Caster}

The FreeWheel caster type is a large diameter and large width pneumatic wheel, which attaches to the wheelchair's footplate. The FreeWheel caster has many of the same advantages as the pneumatic caster type as it has increased contact area with the wheeling surface as well as a soft material type. The large diameter would also likely aid in overcoming tall obstacles that a wheelchair user might face. The FreeWheel lifts the existing front casters off of the ground and tilts the seat of the chair backwards to accommodate the large diameter wheel. The arm to which the FreeWheel is attached also acts in lengthening the base of support of the wheelchair. The tilting of the wheelchair and lengthening of the base change the weight distribution and center of gravity of the chair to relieve weight off of the front caster, leading to improved caster performance. The FreeWheel performed quite well in the human participant trials in the areas of performance time, RPE, and stroke count. However, in phase two of the study it's performance 
was comparable to the other caster types, it also had a rather poor performance in caster penetration for the inclined condition only.

The way in which the FreeWheel redistributes the weight in the wheelchair could possibly have adverse effects on a wheelchair user. Backwards tipping becomes a greater risk as the FreeWheel allows the center of gravity of the user to be moved back. Backwards tipping could be especially likely to occur when ascending a ramp, an activity which already puts a user at risk of such an accident. Weight distribution could also cause complications with existing pressure management systems in place. Also, as the FreeWheel increases the length of the body of the chair, it could affect the overall manoeuvrability of the individual using the chair, forcing them to avoid tight situations.

The FreeWheel is designed in such a way that it can be put on or taken off while sitting in the chair, and can be stored on the back of the seat. Therefore it need not be used on conventional wheeling surfaces or in situations where manoeuvrability is required. However, a combination of flexibility, strength, and skill are required to put on and remove the caster.

\subsubsection{Wheel Blade Caster}

Similarly to the FreeWheel caster type the Wheel Blades are an addition to the existing wheelchair casters. The Wheel Blades are small skis that attach to the bottoms of the existing casters. While the Wheel Blades have the largest contact area of all the caster types tested and had a negligible penetration into the snow surface, they still did not perform better than the other casters in terms of resistance to movement. It is likely due to the large contact area that friction with the wheeling surface led to an increased resistance to movement. It was also observed on the phase-one inclined trials, the participants experienced backwards slipping. When they were 
not engaging the wheel rims, the wheelchair would slip backwards down the ramp. This did not occur with the other caster types, as they would penetrate deeply into the snow-pack holding them in place between propulsive movements.

Unfortunately we were forced to forego testing the Wheel Blades on a bare surface to avoid damaging their underside. The Wheel Blades are very limited in use due to the fact that they are only appropriate to be used on a snow surface, and individuals are likely to encounter exposed sidewalk surface when traveling on urban paths. The result would be putting on and removing the Wheel Blades rather frequently, a task which like the FreeWheel, requires a great deal of flexibility and skill to do.

\subsection{Execution of Methodology}

The methodology used in this study likely could be used to assess wheelchair performance in winter conditions in future studies with some suggested adjustments. In the following sections I will discuss the appropriateness of the performance measures chosen and suggested methodology changes in future studies of this nature. A summary table of the appropriateness of the performance measure can be found at the end of this chapter (Fig. 18)

\subsubsection{Appropriateness of performance measures}

The performance measures chosen for both phases of the study are considered appropriate as the results of this study supported results of previous studies and confirmed the hypothesis. The majority of the metrics were in in agreement with one another. The results revealed that for standard caster designs, significantly decreased performance occurred in the presence of an incline; this result has been previously observed by Koontz et al. (2005), Hurd et al. (2009), and Choi et al. (2015). Similarly when using standard casters, the presence of a 
textured or soft surface resulted in decreased wheelchair performance, which also had previously been observed by Hurd et al. (2009) and Koontz et al. (2005).

Only one of the performance measures did not support the results of previous studies, and that is the measure of perceived exertion. The results of the rating of perceived exertion found that there was no significant difference between incline and flat conditions. This result suggests that the rating of perceived exertion performance measure be removed or improved in future studies.

\subsubsection{Methodology improvements for future studies}

Observations in both phases of the study resulted in suggested performance measures to include in following studies of this nature. In phase one experiment human participants were observed performing risky manoeuvres associated with wheelchair accidents, such as tipping backwards onto the rear wheels and lifting the casters from the ground. Including video analysis to count the instances of risky manoeuvring as well as type of risky manoeuvring associated with the wheelchair components would provide insight into the risk of accident or injury. Also, many participants became stuck in the snow-pack and ceased movement during trials. A method could be developed for video analysis to quantify instances of becoming stuck (where forward motion ceases) and the length of time an individual may become stuck for, and the strategies used for becoming "unstuck".

The rating of perceived exertion clearly confused some of the participants of the study and often participants would rate the difficulty of the skill required to use the wheelchair rather than the amount of exertion that they felt. In future studies it would be advised to make two distinct ratings, one pertaining to task difficulty and the other of perceived physical exertion. A 
rating of task difficulty would help distinguish the difficulties of the skills required to use the four caster types.

It is known that snow exists in different forms in terms of crystal formation as well as other mechanical properties (Mellor, 1974). Temperature cycles as well as compression and cohesion affect the viscous as well as the elastic components of the snow. Information on the mechanical properties of snow exists in a very narrow range of temperatures as well as conditions, which makes it difficult to predict its behaviour. For future the investigators should develop a method for collecting mechanical properties of the snow-pack for the day that they are performing trials to provide a thorough and accurate description of the conditions.

The area of contact with the wheeling surface (contact patch) of each caster type was not considered at the beginning of the study. Calculating the contact patch could be done using formulas suggested by Sharma and Pandy (1996) in their review on tire contact area. Unfortunately during the testing the necessary metrics of tire deflection and material constants were not collected, and these calculations were unable to be made. Smaller wheel contact patches are associated with decreased rolling resistance on hard surfaces, however on soft surface conditions, such as tires on soil in agricultural applications, the effects of contact area become much more complex. As snow is a soft surface, the effects of the contact patch has become less predictable, however it was hypothesized that a larger contact patch would be beneficial in distributing the weight of the wheelchair and would result in a lower caster penetration into the snow-pack. In the future it is suggested that contact patch metrics be collected and considered in the performance of wheelchair casters on snow surfaces. The appropriateness of all the performance measures used has been summarized in the table below (Fig. 18). 


\begin{tabular}{|l|l|}
\hline \multicolumn{1}{|c|}{ Performance measure } & \multicolumn{1}{c|}{ Appropriateness } \\
\hline Performance Time & Good \\
\hline Rating of Perceived Exertion & Needs improvement \\
\hline Impulse & Good \\
\hline Stroke Count & Good \\
\hline Static Resistance & Good \\
\hline Kinetic Resistance & Good \\
\hline Penetration & Good \\
\hline Observations & Good \\
\hline Tire Contact Area & Suggested for future studies \\
\hline Properties of the snow surface & Suggested for future studies \\
\hline Heart Rate & Suggested for future studies \\
\hline Rating of Perceived Skill & Suggested for future studies \\
\hline
\end{tabular}

Figure 18 Summary of performance measures and their appropriateness for assessing wheelchair components in winter conditions.

\subsection{Limitations}

In the following sections the limitations associated with both the first and second phase of the study will be discussed.

\subsubsection{Limitations of Study - Both Phases}

The study was limited in that there was only one wheelchair, set up in one configuration. This is an issue as the wheelchair was not fitted properly for each participant who used it, also it is possible that using a different make, model, or style of wheelchair would have yielded 
completely different results while being tested for these same conditions. No effort was made to recruit participants with a specific body type that would best fit the wheelchair that was used.

Another limitation of the study was the packed snow condition. For both phases of the study it was difficult to maintain the snow pack consistently between days and between trials. While testing on different days, the temperature affected the properties of the snow such as cohesion (sticky vs. powdery), and its hardness. It was also difficult to completely reset the experimental setup between trials as the snow would become more densely packed where the wheelchair casters and tires had rolled over it, and simply re-packing the snow by foot did not return it to its initial condition. The snow pack tended to be deeper at the entrance of the ramp, and was more loose and powdery compared to all other locations that could potentially affect the results of the study.

\subsubsection{Limitations of Experimental Phase 1}

Using non-experienced wheelchair users as participants in the experiment might be considered a limiting factor. Individuals who are novice wheelchair users will likely have not developed the complex skills necessary to manoeuver the wheelchair in adverse environments, such as overcoming difficult terrain, or operating the wheelchair while wearing gloves. Future studies of this type should consider using experienced wheelchair users as participants.

A factor of the phase 1 experiment that may be considered limiting is that specialized instrumentation was not available. Previous studies made use of an instrumented wheel, known as the SMARTwheel, to collect force, acceleration, and power measurement. Unavailability of monetary funding, as well as the possibility that the SmartWheel would not perform in sub-zero temperatures, led to the design of an alternative system for force measurement. The force- 
sensing array on the palms previously was found to have similar force collection trends as the SmartWheel, however, was not able to collect all the same metrics (Morrow et al., 2013). Based on the findings of this latter study, it was decided that the designed system would adequately collect impulse information.

Finally, during the experiment it was noted that many of the participants seemed confused with the Borg Scale rating, and would often rate how difficult they found the task to complete instead of rating their perceived physical exertion. Examples of skills required of the different caster types: the FreeWheel increases the difficulty of navigating turns due to the fact that it increases the length of the wheelchair, the Wheel Blades kept the casters from sinking into the snow pack, however it resulted in backwards slipping on the incline condition, Solid and Pneumatic caster penetrated into the packed snow and required backwards weight shifting to relieve the force on the front casters.

\subsubsection{Limitations Phase 2}

A major limitation of this experiment was the distribution of the weight in the seat of the wheelchair. Four $20 \mathrm{~kg}$ suitcase weights were loaded onto the seat of the wheelchair, and no attempts were made to make the distribution of the weight resemble that of an active wheelchair user. Center of gravity has the potential to greatly affect the behaviour of the stability and the manoeuvrability of a manual wheelchair. It is also worth noting that a skilled wheelchair user would be able to manage the distribution of weight on the drive wheels and casters by leaning forwards and backwards in different situations, such as climbing ramps and overcoming obstacles. Having a static weight in the wheelchair did not necessarily mimic a real-world scenario, and it is possible that different results could be found if the wheelchair were weighted differently. 
Another limitation worth noting of this experiment is that it was performed within a small range of temperatures. The mechanical properties of snow are affected by variables such as temperature and moisture content (Mellor, 1974), and it is possible that different results could be found if the experiments were repeated at a different temperature. Finally, another limitation of the experiment is that the tests were performed at a single velocity $(0.25 \mathrm{~m} / \mathrm{s})$. While this speed falls within the range of the velocities collected in phase 1 of the study, it is possible that other results could be found if the wheelchair were pulled at different rates because of the viscous (speed dependant) properties of the snow (Mellor, 1974).

\subsection{Future directions}

The methodology developed was found to be acceptable in assessing wheelchair performance. Now, future caster designs can be tested using the same technique to determine their appropriateness for use in winter conditions or for other wheeling surface types. While this study did not find that any specific caster completely mitigated the negative effects of packed snow on all the performance measures, this study has given insight into which design aspects had influence on the performance measures. Using the methodology developed, future studies could be performed on different wheelchair components such as drive wheels or seating systems. Alternatively, the methodology could be used to test wheelchair performance on surface types other than snow, such as gravel or woodchips.

Another suggestion for an area of study is the effect of various casters on caregiver performance. While many manual wheelchair users are able to self-propel, others rely on caregivers to push their manual wheelchair, such as the elderly or those with limited upper body strength. Future areas of study should include the effect of assistive technology components on the individuals who provide care to those with disabilities. 


\subsection{Conclusion}

Based on the results and observations of this study it can be concluded that the FreeWheel caster type had the best performance on the snow-packed surface condition within the most performance measures. Although the FreeWheel caster had the best performance over the other caster types, it was unable to perform at a comparable level to standard solid casters on a smooth level surface. This result indicates that using the chosen casters adaptations on a manual wheelchair will not allow an individual to return to a level of functioning as though no winter barriers existed. It is possible that future caster design may completely neutralize the effects of packed snow, but it is likely that modifications of other components such as hand rims or powered wheels may also be necessary to allow individuals to use manual wheelchairs in winter conditions without the effects of increased biomechanical strain.

The methodology that was designed to assess the four caster types was based on the HAAT model of assistive technology design, and focused on both human factors and mechanical performance in natural context. The results of the experiments were validated as performance decreased when using standard solid casters on incline conditions as well as snow-packed surface conditions. These results are in agreement with studies previously performed, where the presence of an incline and rough surface texture had negative effects on human performance measures.

Using the results of this study, further design of wheelchair components may be done. New designs and scenarios may be tested using the proposed methodology for not only caster wheels, but other components such as propulsion aides or power assist units. Through the use of assistive technology and modified wheelchair components individuals may experience an improved quality of life, by overcoming barriers associated with winter conditions. 


\subsection{References}

Arim, R. 2015. A Profile of Persons with Disabilities Among Canadians Aged 15 Years Or Older, 2012.

Borg, G. 1998. Borg's perceived exertion and pain scales. Human kinetics.

Choi, Y. O., H. Y. Lee, M. H. Lee and O. H. Kwon. 2015. Effects of ramp slope on physiological characteristic and performance time of healthy adults propelling and pushing wheelchairs. Journal of physical therapy science 27(1): 7.

City of Winnipeg. 2011. Policy on snow clearing and ice control. Section C.

Cook, A. M. 2008. Cook \& Hussey's assistive technologies : principles and practice. 3rd ed. Albert M. Cook and Jan Miller Polgar.. ed. St. Louis, Mo.: St. Louis, Mo. : Mosby Elsevier.

Eston, R. G., B. L. Davies and J. G. Williams. 1987. Use of perceived effort ratings to control exercise intensity in young healthy adults. European journal of applied physiology and occupational physiology 56(2): 222-224.

Gaal, R. P., N. Rebholtz, R. D. Hotchkiss and P. F. Pfaelzer. 1997. Wheelchair rider injuries: causes and consequences for wheelchair design and selection. Journal of rehabilitation research and development 34(1): 58-71.

Hurd, W. J., M. M. Morrow, K. R. Kaufman and K. An. 2009. Wheelchair propulsion demands during outdoor community ambulation. Journal of Electromyography and Kinesiology 19(5): 942-947. 
Kirby, R. L., S. A. Ackroyd-Stolarz, M. G. Brown, S. A. Kirkland and D. A. MacLeod. 1994. Wheelchair-related accidents caused by tips and falls among noninstitutionalized users of manually propelled wheelchairs in Nova Scotia. American Journal of Physical Medicine \& Rehabilitation 73(5): 319-330.

Koontz, A. M., R. A. Cooper, M. L. Boninger, Y. Yang, B. G. Impink and Van Der Woude, Lucas HV. 2005. A kinetic analysis of manual wheelchair propulsion during start-up on select indoor and outdoor surfaces. Journal of rehabilitation research and development 42(4): 447.

Lemaire, E. D., P. A. O'Neill, M. M. Desrosiers and D. G. Robertson. 2010. Wheelchair ramp navigation in snow and ice-grit conditions. Archives of Physical Medicine and Rehabilitation 91(10): 1516-1523.

Lindsay, S. and N. Yantzi. 2014. Weather, disability, vulnerability, and resilience: exploring how youth with physical disabilities experience winter. Disability and rehabilitation.

MAXmobilityUSA. 2012. MAX Mobility - Propulsion Training 101. YouTube. Available at: https://www.youtube.com/watch?v=BD9kp4u89Gc\&nohtm15=False. Accessed November 2014.

Mellor, M. 1974. A review of basic snow mechanics. US Army Cold Regions Research and Engineering Laboratory.

Morrow, M. M., W. J. Hurd, K. R. Kaufman and K. An. 2010. Shoulder demands in manual wheelchair users across a spectrum of activities. Journal of Electromyography and Kinesiology 20(1): 61-67. 
Morrow, M. M., M. P. Van Straaten, K. D. Zhao, B. A. Cloud and K. R. Kaufman. 2013. Manual wheelchair user hand force measurement in the field: a preliminary report. In RESNA annual conference, Division of Orthopedic Research, Mayo Clinic, Rochester, MN: RESNA.

Purvis, J. and K. Cukiton. 1981. Ratings of perceived exertion at the anaerobic threshold. Ergonomics 24(4): 295-300.

Ripat, J. D., C. L. Brown and K. D. Ethans. 2015. Barriers to wheelchair use in the winter. Archives of Physical Medicine and Rehabilitation.

Salentines, B. A. 2012. Manual versus power wheelchair propulsion: quality of life and selfperception. PhD diss. University of Illinois at Urbana-Champaign.

Sauret, C., J. Bascou, N. De Saint Remy, H. Pillet, P. Vaslin and F. Lavaste. 2012. Assessment of field rolling resistance of manual wheelchairs. Journal of Rehabilitation Research and Development 49(1): 63-74.

Sharma, A. K. and K. Pandey. 1996. A review on contact area measurement of pneumatic tyre on rigid and deformable surfaces. Journal of Terramechanics 33(5): 253-264.

Shirado, O., M. Shundo, K. Kaneda and T. E. Strax. 1995. Outdoor winter activities of spinal cord-injured patients: With special reference to outdoor mobility. American Journal of Physical Medicine and Rehabilitation 74(6): 408-414.

Veeger, H., L. Rozendaal and F. Van Der Helm. 2002. Load on the shoulder in low intensity wheelchair propulsion. Clinical Biomechanics 17(3): 211-218. 
World Health Organization. 2001. International classification of functioning, disability and health: ICF. World Health Organization.

Appendix A: Ethics Documentation 
$\square$ Joint-Faculty REB

Check the appropriate REB for the Faculty or Department of the Principal Researcher. This form, attached research protocol, and all supporting documents, must be sent to the Human Ethics Coordinator, Margaret.Bowman@ad.umanitoba.ca, CTC Building, 208 - 194 Dafoe Road, 474-7122.

Winnipeg, MB R3T 2N2

Phone: (204) 474-7122

Fax: (204) 269-7173

Protocol\#

(For HES Admin.)

CORE/CHRPP

(For HES Admin.)

Michele Sara Berthelette

Principal Investigator

Status of Principal Investigator(s): please check:
Faculty
Student Graduate
WRHA Affiliate
$\square$ Post-Doc
Undergraduate
$\square$ Other Specify

Co-investigator(s): Specify affiliation (Separate with semi colon)

E2-376, Biosystems Engineering

Address (to receive Approval Certificate)

Postal Code (if off campus)

(204)226-5586 umberthm@cc.umanitoba.ca

Phone Email

Influence of manual wheelchair caster design on the ability to navigate snow covered surfaces.

Planned period of research (if less than one year) Jan 1, 2015

Project Title
Start Date

\section{Type of research (Please select):}

Faculty Research

Self-funded

Sponsored

Agency

UM Project \#

Find your UM Project \# [funded only] visit: http://umanitoba.ca/research/ors/mrt-faq.htm
Administrative Research

Central

Unit-based

\section{Student Research \\ Honour's Thesis \\ Master's Thesis \\ Doctoral Thesis \\ Class Project \\ Course Number}

\section{Is this submission a follow-up to an existing RPA (Request for Preliminary Access to Grant Funding) form?}

No $\square$ Yes $\square$ If yes, please identify protocol\#

\section{A. Signature of Principal Investigator}

For student research: If thesis, this proposal is ap proved by department/thesis committee. By signing, the Thesis Supervisor/Course Instructor indicates that they have reviewed and approved this application.

\section{B. Name of Thesis Advisor Dr. Danny Mann} (Required if thesis research)

\section{Signature}

D. Course Instructor

(Required if class project)

\section{E. Signature}

Persons signing assure responsibility that all procedures performed under the protocol will be conducted by individuals responsibly entitled to do so, and that any dêj 3 ation from the protocol will be submitted to the REB for its approval prior to implementation. Signature of the thesis advisor/course instructor indicates that student researchers have been instructed on the principles of ethics policy, on the importance of adherence to the ethical conduct of the research according to the submitted protocol (and of the necessity to report any deviations from the protocol to their advisor/instructor). 


\section{Ethics Protocol Submission Form}

\section{(Basic Questions about the Project)}

The questions on this form are of a general nature, designed to collect pertinent information about potential problems of an ethical nature that could arise with the proposed research project. In addition to answering the questions below, the researcher is expected to append pages (and any other necessary documents) to a submission detailing the required information about the research protocol (see page 4).

1. Will the participants in your study be UNAWARE that they are participants?

2. Will information about the participants be obtained from sources other than the participants themselves?

3. Are you and/or members of your research team in a position of power vis-a-vis the participants? If yes, clarify the position of power and how it will be addressed.

4. Is any inducement or coercion used to obtain the participant's participation?

5. Do participants identify themselves by name directly, or by other means that allows you or anyone else to identify data with specific participants? If yes, indicate how confidentiality will be maintained. What precautions are to be undertaken in storing data and in its eventual destruction/disposition.

6. If participants are identifiable by name, do you intend to recruit them for future studies? If yes, indicate why this is necessary and how you plan to recruit these participants for future studies.

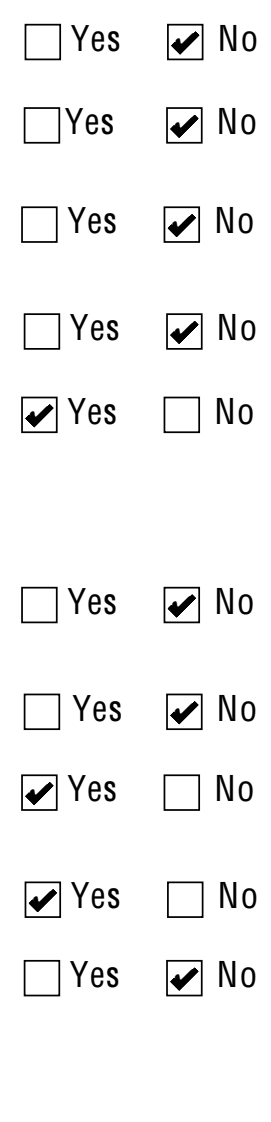

11. Is deception involved (i.e., will participants be intentionally misled about the purpose of the study, their own performance, or other features of the study)?

12. Is there a possibility that abuse of children or persons in care might be discovered in the course of the study? If yes, current laws require that certain offenses against children and persons in care be reported to legal authorities. Indicate the provisions that have been made for complying with the law.

13. (a) Does the study include the use of personal health information? The Manitoba Personal Health Information Act (PHIA) outlines responsibilities of researchers to ensure safeguards that will protect personal health information. If yes, indicate provisions that will be made to comply with this Act (see document for guidance: http://www.gov.mb.ca/health/phia/).

13. (b) PHIA requires that all employees, students, or agents who handle or are exposed to personal health information take PHIA Orientation and sign a pledge of confidentiality that acknowledges that they are bound by written policy and procedures.

Has PHIA Orientation and pledge-signing been completed by all employees, students, and agents?

If "No," the Principal Investigator should contact UM Access \& Privacy Coordinator's Office to make arrangements, fippa@umanitoba.ca

Where individuals have not completed PHIA Orientation and signed a pledge, and for the purpose

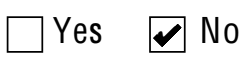
No

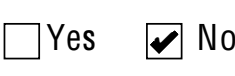
No

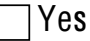

No of ensuring that they do, Principal Investigator's contact information will be provided to the University Access \& Privacy Coordinator's Office. 
Provide additional details pertaining to any of the questions above for which you responded "yes", excluding question 13 (b). Attach additional pages, if necessary.

5. Maintaining confidentiality

After obtaining informed consent, all participant data will be coded using an anonymous code (P01, P02, etc.) and stored in locked filing cabinets or on password-protected computers. All consent forms will be stored in a separate locked cabinet. Only members of the Agricultural Ergonomics Lab (Dr. Danny Mann, Michele Berthelette, Aadesh Rakhra, and Behzad Bashiri) will have access to any lists that contain identifying information. All papers and electronic files containing personal information (consent forms, video tapes, and demographic questionnaires) will be shredded, deleted, or destroyed five years after the results of the study are published.

Results will be presented at academic conferences, invited presentations, and published in peer-reviewed academic journals. In all cases only group means will be presented. This data contains no identifiable information and therefore anonymity will be maintained.

\section{Physical Stress}

Participants will undergo moderate physical stress during the experiment, they will be asked to propel a manual wheelchair over snow terrain. Participants will be exposed to cold temperatures, but the experiment will take place indoors in an un-insulated building which shields them from harsh winter conditions such as wind and snow.

Participants will be encouraged to wear warm clothing and will be provided with gloves to wear during the course of the experiment. At any point during the experiment participants will have access to a heated room where they can take shelter from the cold. Participants may also experience muscle fatigue during the experiment, and will be encouraged to take rest as needed. Participants may choose to end their participation at any time without any negative repercussions.

\section{Personal Safety of Participants}

Participants may be at risk of tipping or falling from the manual wheelchair when performing the experiment. There will be hand-rails on either side of the wheeling surface that the participants may grab on to if they sense themselves falling. The participants will not be strapped into the chair, so if they sense themselves tipping forward they will be encouraged to simply step out of the chair. The wheelchair used in the study will be fitted with an anti-tip bar that will prevent backwards falls. 


\section{Ethics Protocol Submission Form}

\section{(Required Information about the Research Protocol)}

Applications for ethics approval should include the following information and be presented in the following order, using the headings indicated. Each page should be numbered, by hand if necessary. To ensure the most rapid approval possible, please refer to the detailed application guidelines posted on the HES website.

1. Summary of Project: Attach a detailed but concise (one typed page) outline of the purpose and methodology of the study, describing precisely the procedures and tasks in which participants will be asked to engage.

2. Research Instruments: Include next a concise summary of the research instruments, especially any risks they may pose to participants. In a separate appendix, provide copies of all materials (e.g., questionnaires, tests, interview schedules, instructions, etc.) to be given to participants and/or third parties.

3. Participants: Provide a detailed description of the participants, their numbers, and how they will be recruited . Include copies of all written recruitment communications and scripts of all oral recruitment communications. Are there any characteristics of the participants that make them especially vulnerable or require extra precautions?

4. Informed Consent: Normally, consent in writing is required. Attach a copy of the consent form(s) on department/ faculty letterhead (see detailed guidelines regarding consent forms). Different consent forms for different groups of participants in the same study are frequently required. If written consent is not to be obtained, indicate why and the manner by which participants' consent (verbally) or assent to participate in the study will be obtained. How will the nature of the study, the questions they will be asked, the tasks in which they will engage, and the risks to which they will be exposed be explained to participants before they give informed consent? How will consent be obtained from parents or legal guardians of participants unable to give legal consent on their own? If confidential records will be consulted, indicate the nature of the records, and how participants' consent for accessing such records will be obtained. If it is essential to the research, indicate why participants will not be made aware that their records are being consulted.

5. Deception: Deception refers to the deliberate withholding of essential information or the provision of deliberately misleading information about the research or its purposes. If the research involves deception, the researcher must provide detailed information on the extent and nature of deception and why the research could not be conducted without it. This description must be sufficient to justify a waiver of informed consent.

6. Feedback/Debriefing: Normally, feedback should be given to participants about the research immediately after data collection, so as to make their experience as educational as possible. How will the feedback be provided and by whom? If feedback will not be given, please explain why feedback is not planned. In addition, steps should be taken to provide participants with a brief, non-technical summary of study results as soon as possible after the data collection phase of the study is completed (normally a few weeks or months). Participants should be given a choice of how they wish to receive a summary and should be told approximately when (MMYY) to expect it.

7. Risks and Benefits: Are there any risks (physical, psychological, and/or emotional) to participants, or to a third party? If yes, provide a description of the risks, the steps that will be taken to mitigate them, and the steps that will be taken to ameliorate any actual harm to participants, including (if appropriate) providing a list of helpful resources. The researcher should also describe any direct, counter-balancing benefits for participants of the proposed study.

8. Anonymity or Confidentiality: Describe the nature of the data that will be collected, how it will be stored, and who will have access to it. Anonymous data contains no personal identifiers and, thus, poses no risk of identification to participants. Confidential data contains personal identifiers and carries with it an inherent risk of identification. Therefore, in the latter case steps must be taken to prevent unauthorized persons from linking data to individual participants, up to and including dissemination of findings. Confidential data should be destroyed or rendered anonymous as soon as it is no longer necessary scientifically to link data with individual participants. Anonymous data may be kept indefinitely. Please describe your plans in this regard, including an approximate date (MMYY) by which any confidential data will be destroyed.

9. Compensation: Will participants be compensated for their participation? Reasonable compensation may be provided to defray actual costs associated with study participation and/or as an honorarium for the time and effort of participants. However, it may not be sufficient to act as a significant inducement to participation.

10. Dissemination: How will study results be disseminated, to whom, and for what intended purposes? Dissemination plans must be agreed to in general by participants and must not jeopardize their right to confidentiality unless they haveexplicitly waived this right. 


\section{Review your submission according to this: \\ Checklist}

Please note that your application will be returned to you for completion if ANY of the components below are not completed. In preparing their submission, applicants are strongly encouraged to first review the detailed application Guidelines available on the Human Ethics website.

All information requested on the first page completed in legible format (typed or printed).

If student research, signatures of the Faculty Research Supervisor or email confirmation of approval from the Research Supervisor.

Responses to all 13 questions on pages 2-3 of Ethics Protocol Submission form, INCLUDING SEPARATE, DETAILED ANSWERS TO ANY QUESTIONS FOR WHICH YOUR RESPONSE WAS "YES"

Detailed information requested on page 4 of the Ethics Protocol Submission Form in the numbered order and with the headings indicated, using no smaller than 11 font AND WITH ALL PAGES NUMBERED (HANDWRITTEN NUMBERS ARE ACCEPTABLE).

Copies of all written communications to participants (including recruitment materials) on Department/ Faculty letterhead and/or scripts of all oral communications.

Research instruments: Appended copies of all instruments and other supplementary material to be given to participants.

Evidence of completion of CORE or CHRPP tutorial or acknowledgment that approval will not be granted until tutorial is completed.

Copy of this checklist. 


\section{Instrument Information}




\section{Participant Training Video}

Participants will be trained on how to propel a manual wheelchair using the following youtube video:

https://www.youtube.com/watch?v=BD9kp4u89Gc\&list=PLX_PLpyalkSGfn9ETMWAs WEK1YNjPon7i\&index $=2$

The video is presented by Max-Mobility USA. The video demonstrates a good technique for propelling a wheelchair, by encouraging users to use long and smooth strokes. The video makes the movements very easy to understand, and therefore makes a good training video for the participants. In the description of the video they state, "Technique presented in this video is interpreted from the PVA Clinical Practice Guidelines and represents current best practice."

\section{Borg Scale}

After every trial, participants will be asked to rate their perceived physical out of a ten point scale. Participants will be given this scale as a reference:

\begin{tabular}{|c|c|}
\hline \multicolumn{2}{|c|}{$\begin{array}{c}\text { 1-10 Borg Scale of } \\
\text { Perceived Physical } \\
\text { Exertion }\end{array}$} \\
\hline 0 & Rest \\
\hline 1 & Very Easy \\
\hline 2 & Easy \\
\hline 3 & Moderate \\
\hline 4 & Somewhat Hard \\
\hline 5 & Hard \\
\hline 6 & \\
\hline 7 & Very Hard \\
\hline 8 & \\
\hline 9 & \\
\hline 10 & Maximal \\
\hline
\end{tabular}




\section{Recruitment Poster}




\title{
B \\ UnIVERSITY of MANiTOBA \\ Manual Wheelchair Design: \\ Caster Wheel Modifications for Winter Conditions
}

\author{
Biosystems Engineering currently recruiting \\ participants for a study:
}

Purpose of Study: We are interested in studying the influence of caster wheel design on a user's ability to navigate snow-covered surfaces.

Role of Participant: You will be trained on using a manual wheelchair and will be asked to propel yourself over various surface types. We will monitor signs of physical exertion, and you will be asked to fill out a demographic questionnaire. An honorarium will be awarded to you for volunteering your time.

Time and Location: The study will take place in a non-insulated building on the Fort Garry campus during the winter months, the time commitment is expected to be 2-3 hours. You will be asked to wear appropriate clothing for the conditions (jacket, ski pants, toque).

Eligibility: Individuals between the ages 18-40, with full mobility of upper limbs.

Contact Information: Please e-mail Michele: umberthm@myumanitoba.ca, or call (204)474-7446 if you are interested in participating in the study, and would like to receive more details.

This research has been approved by the Education/Nursing Research Ethics Board. If you have any concerns of complaints, you may contact the Human Ethics Coordinator at 204-474-

7122 or email: margaret.bowman@umanitoba.ca

Winter Wheelchair Study

umberthm@myumanitoba.ca

1(204)-474-7446 
Course Instructor Consent 
E-mail script, requesting permission to present opportunity to participate to a classroom of students:

Dear Prof. [Name]

I am contacting you to request permission to present a research opportunity to the students of your class, [class name, BIOE\#\#\#\#]. I would like to take the first 2-3 minutes of your class to present my current research, and to recruit participants.

My current research if focused on manual wheelchair design, specifically modification to caster wheels for winter conditions. An experiment requiring human participants will be carried out to explore the influence of different front caster types on the ability to navigate snow surface conditions.

Dr. Mann is my advisor in this project and if you have any concerns or questions you may contact him through e-mail (Danny_Mann@umanitoba.ca) or phone(204-474-7149).

This research has been approved by the Education/Nursing Research Ethics Board. If you have any concerns of complaints, you may contact the Human Ethics Coordinator at 204-4747122 or email: margaret.bowman@umanitoba.ca

Please let me know if you are interested in allowing me to present, and we can arrange a date that works for both of us.

Thank you,

Michele Berthelette 
Classroom Script 
Script to be read out loud to students in a Biosystems Engineering classroom, a copy of the recruitment poster would be left at the front of the class.

Hello, my name is Michele Berthelette and I am a graduate student of Biosystems engineering. I am here today to tell you about my current research work, and to present you with the opportunity to participate in an experiment.

My work is focused on design of manual wheelchairs, and specifically designing them for use in winter conditions. My current experiment that I am running focuses on modifications the front caster wheels. I'm interested in studying the interaction between the user and the wheelchair, as well as the interaction between the wheelchair and the wheeling surface.

If you participate in this study, you will be trained on how to propel a manual wheelchair, and will be asked to wheel over a variety of surfaces (bare, snow-covered, flat, and inclined) while using different style caster wheels. We will monitor signs of physical exertion (such as heart rate and muscle activity), we will weigh you along with all the equipment you will be wearing at the time, and we will ask you some demographic information.

The experiment is estimated to take 2-3 hours, and you would be awarded an honorarium for volunteering your time. "This research has been approved by the Education/Nursing Research Ethics Board".

Your choice to participate in this study will not affect your grade or treatment in this class in any way. If you are interested in participating or have any questions you would like to ask, you can contact me over the phone or through e-mail (I have left my contact information at the front of the class). Are there any questions?

Thank you for your time. 


\section{Interest Script}




\section{[Script 1]}

This script would be a response to a person who expresses interest in participating in the study, this script can be read during a phone conversation or can be sent in reply to an email of interest.

Hello, and thank you for your interest in participating in the study.

As a participant in the study, you would be asked to propel a manual wheelchair over various surface types including: bare/snow-covered surfaces, and flat/inclined surfaces.

Before the study begins you will be asked to wear a heart rate monitor against your chest and under your shirt. The experimenter will also place small force sensors on the palms of your hands using medical tape. During the experimental trials you will be video recorded so that we may have a record of events with which we can correlate to other data (i.e., a transition from snow covered surface to bare surface). Finally, after the experiment, you will be asked to fill a demographic questionnaire.

The study will take place in an un-insulated building and is estimated to take 2-3 hours. We ask that you wear weather appropriate clothing such as a winter jacket, ski pants, and a toque. We also ask that during the experiment you wear the gloves that we provide to ensure warmth and good grip on the wheel rims. At any point during the study you are welcome to take a break if you are tired or to warm up in a heated room.

If you have any questions please feel free to ask. I have attached a copy of the consent form for you to review. If you are interested in participating, we will schedule a time for you to come in.

Michele Berthelette

[Consent form attachment]

\section{[Script 2A]}

This is an e-mail message for a person that shows continued interest in participating in the study. This e-mail will contain an attached consent form and a map to the location of the study.

Thank you for your continued interest,

[provide answers for any questions participant may have]

I have attached a copy of the consent form for you to review. The experiment will take place in the "Animal Science Equipment Shed" (please see google maps link). What day are you available to participate?

Michele Berthelette 
[Script 2B]

This is a phone script for a person that shows continued interest in participating in the study.

Thank you for your continued interest,

[provide answers for any questions participant may have]

A copy of the consent form can be provided in advance if you wish to review it before coming in, or you can review it upon arrival. The experiment will take place in the "Animal Science Equipment Shed", located on Service Road 2 SW st., off of Innovation drive. What day are you available to participate?

\section{[Script 2C]}

This script is for a person that no longer has an interest in participating in the study. This can be used as a phone script, or an e-mail script.

Thank you for your consideration. 


\section{Informed Consent Form}




\title{
Influence of manual wheelchair caster design on the ability to navigate snow covered surfaces.
}

Principal Investigator:

\author{
Michele Berthelette \\ Graduate Student, Department of Biosystems Engineering \\ University of Manitoba
}

204-474-7446

umberthm@cc.umanitoba.ca

Advisor:

Dr. Danny Mann, Ph.D., P.Eng

Professor \& Head

Department of Biosystems Engineering

204-474-7149

Danny.Mann@umanitoba.ca

You are being asked to participate in a Research Study in which Video of you will be used. The information contained in Video is considered personal Information as they present recorded information in which you may be identified. Please take your time to review and read this consent form carefully and any accompanying information. It should give you the basic idea of what the research is about and what your participation will involve. If you would like more detail about something mentioned here, or information not included here, you should feel free to ask the investigator. Although the information captured in video and pictures is non-anonymous, confidentiality will protected by restricting access to the video and to personal information such as the names of the participants or the institutions in which data will be captured. Video used for publication and conference presentation will be anonymized by obscuring facial features.

PURPOSE: We are interested in learning the effects of various wheelchair caster types and their influence on a user's ability to navigate snow conditions. We are interested in studying the wheelchair user's signs of physical exertion, as well as the wheelchair's interaction with the snow surface. 
DESCRIPTION: During the study, you will be asked to propel a manual wheelchair over various surface types including: bare or snow covered, and flat or inclined surfaces. Before the study begins you will be asked to wear a heart rate monitor against your chest and under your shirt. The experimenter will also place small force sensors on the palms of your hands to measure force transfer. We ask that during the experiment you wear the gloves that we provide to ensure warmth and good grip on the wheel rims. Before you begin the experiment we will provide some training on how to propel the wheelchair, and allow you to practice.

During the experiment, one trial consists of propelling the wheelchair for a 24-foot interval. Each trial will be video recorded to gain information on event timing within force and heart rate data being collected, as well as identifying events such as becoming stuck in the snow-pack. After every trial you will be asked to rate your exertion on a 10-point scale. You are encouraged to take breaks for recovery and from the cold whenever needed.

Following the experiment, you will be asked to fill out a brief demographics questionnaire, which includes questions about your age, gender, and handedness. Finally, you will be weighed while wearing all of the equipment.

The whole procedure will take 2-3 hours to complete.

RISKS AND BENEFITS: There are some risks involved in the tasks you will perform, including exposure to cold conditions, and physical exertion. We encourage you to take breaks from the experiment whenever you feel tired or cold. There is a risk of falling while you perform wheelchair manoeuvres; we encourage you to use handrails and to place your feet on the ground to stabilize yourself when you feel it is necessary. The wheelchair is equipped with an anti-tip bar to prevent falling backwards from the wheelchair.

Your participation in this study will help us examine the influence of wheelchair caster design on mobility in winter conditions. This study could potentially influence future wheelchair designs to be better suited for winter surfaces.

COSTS AND PAYMENTS: There are no fees or charges to participate in this study. You will receive a $\$ 20$ honorarium as thanks for donating your time.

CONFIDENTIALITY: Your information will be kept confidential. Once you begin the study a code number will refer to your results. All files containing identifying information, including video recording files) will be stored in a locked cabinet separate from data with your code number. All videos will remained stored on a hard drive and will only be shared in person between Michele Berthelette and her advisor, videos will not be shared over internet connections. Only Michele Berthelette and her advisor, Dr. Danny Mann, will have access to any lists that contain identifying information. 
Results will be presented at academic conferences, invited presentations, and published in peerreviewed academic journals. This data contains no identifiable information and therefore your anonymity will be maintained. Five years after the publication of the results of the study, all paper and electronic files containing personal information will be destroyed by Dr. Mann.

VOLUNTARY CONSENT: If you do not wish to participate in the study, you are free to leave without consequence and we thank you for your consideration. You may withdraw at any point during the study in person, or before the study begins by e-mail. If you choose to withdraw from the study all personal information collected will be destroyed. The decision to withdraw from the study will not have penalties, meaning the honorarium will still be paid. You are free to refrain from answering any questions you prefer to omit, without prejudice or consequence.

In signing this document $I$ freely agree to participate in a research study in which video recordings containing my image may be distributed to: lead investigator Michele Berthelette and her advisor, and may be used in the following contexts: published in academic journals (anonymized by blurring facial features), and presented at conferences (anonymized by blurring facial features). $I$ have been told that my name will not appear in any report or publication resulting from this study. I have been advised that while all feasible precautions are being taken to restrict the use of this video-data, it is not possible to fully guarantee that distributed materials, especially those distributed via the Internet, will always be used for intended purposes.

I have read this consent form. I have had the opportunity to discuss this research study with the investigator. I have had all my questions answered by them in language I understand. The risks and benefits have been explained to me. I believe that I have not been unduly influenced by any study team member to participate in the research study by any statements or implied statements. Any relationship (such as employer, supervisor or family member) I may have with the study team has not affected my decision to participate and that I may choose to withdraw my consent and decline to be recorded and to participate in any activity related to this study at any time, without penalty, prejudice or consequence. I understand that I will be given a copy of this consent form after signing it. I authorize the inspection of any of my records that relate to this study by the University of Manitoba.

By signing this consent form, I have not waived any of the legal rights that I have as a participant in a research study and $I$ have not released the researchers, sponsors, or involved institutions from their legal and professional responsibilities. 
Your signature on this form indicates that you have understood to your satisfaction the information regarding participation in the research project and agree to participate as a subject. In no way does this waive your legal rights nor release the researchers, sponsors, or involved institutions from their legal and professional responsibilities. You are free to withdraw from the study at any time, and/or refrain from answering any questions you prefer to omit, without prejudice or consequence. Your continued participation should be as informed as your initial consent, so you should feel free to ask for clarification or new information throughout your participation. The University of Manitoba may look at your research records to see that the research is being done in a safe and proper way.

This research has been approved by the Education/Nursing REB If you have any concerns or complaints about this project you may contact any of the above-named persons or the Human Ethics Coordinator (HEC), Margaret Bowman at 474-7122 or email at margaret.bowman@ad.umanitoba.ca.

A copy of this consent form has been given to you to keep for your records and reference.

Participant Signature Date

Researcher Signature Date

Please indicate if you would wish to receive a summary of the findings of this study: Yes No

Mode of delivery: e-mail/phone: 


\section{Participant Coding Sheet}




\begin{tabular}{|l|l|l|l|l|}
\hline $\begin{array}{l}\text { Participant } \\
\text { Number }\end{array}$ & Gender (M/F) & $\begin{array}{c}\text { Handedness } \\
\text { (L/R) }\end{array}$ & Age & Weight \\
\hline P01 & & & & \\
\hline P02 & & & & \\
\hline P03 & & & & \\
\hline P04 & & & & \\
\hline P05 & & & & \\
\hline P06 & & & & \\
\hline P07 & & & & \\
\hline P08 & & & & \\
\hline P09 & & & & \\
\hline P10 & & & & \\
\hline P11 & & & & \\
\hline P12 & & & & \\
\hline P13 & & & & \\
\hline P14 & & & & \\
\hline P15 & & & & \\
\hline
\end{tabular}


Appendix B: Raw Data 
Rating of Perceived Exertion ( $\mathrm{n} / 10)$

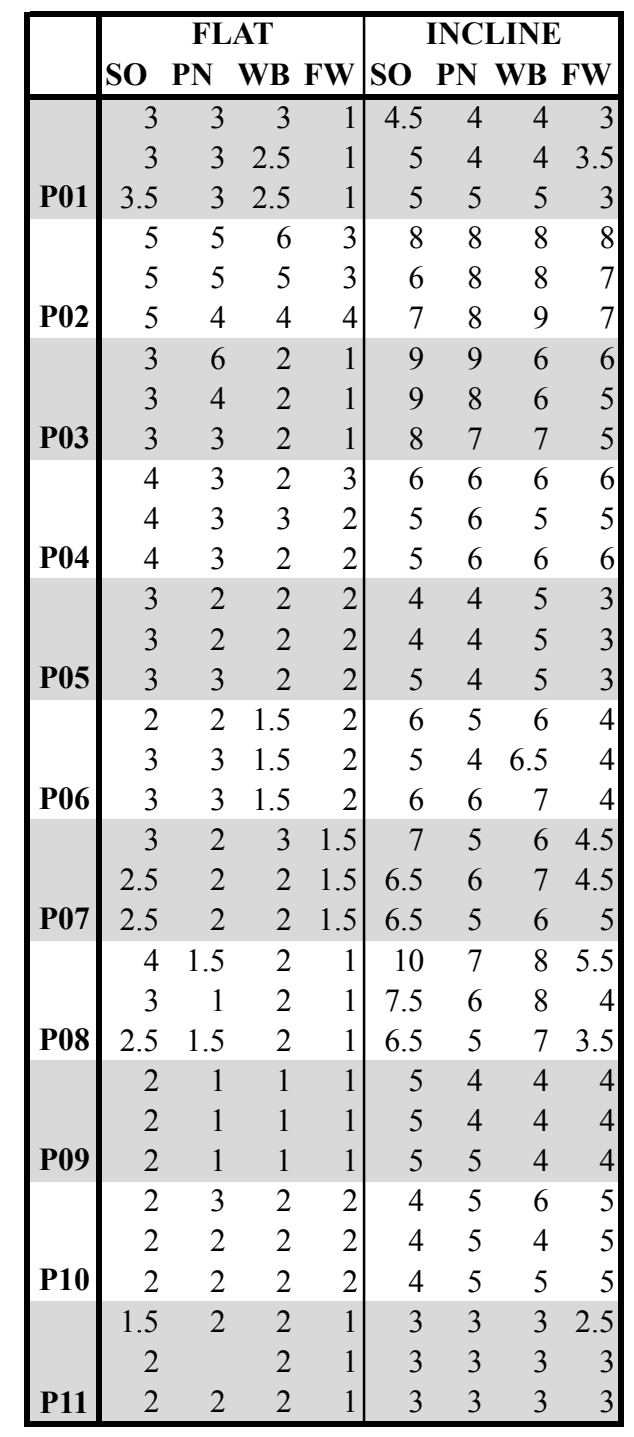




\section{Performance Time (s)}

\begin{tabular}{|c|c|c|c|c|c|c|c|c|c|c|c|c|c|c|}
\hline & \multicolumn{8}{|c|}{ SNOW } & \multicolumn{6}{|c|}{ BARE } \\
\hline & \multicolumn{4}{|c|}{ Flat } & \multicolumn{4}{|c|}{ Incline } & \multicolumn{3}{|c|}{ Flat } & \multicolumn{3}{|c|}{ Incline } \\
\hline & SO & PN & WB & FW & SO & PN & & FW & SO & PN & FW & SO & PN & FW \\
\hline \multirow{5}{*}{ P01 } & 15.11 & 14.84 & 12.27 & 5.03 & 25.05 & 42.14 & 44.21 & 13.41 & 3.43 & 4.17 & 3.27 & 6.74 & 13.31 & 5.40 \\
\hline & 9.94 & 14.64 & 10.81 & 5.03 & 17.75 & 28.19 & 20.05 & 13.71 & 4.60 & 4.73 & 3.03 & 7.94 & 3.44 & 5.17 \\
\hline & 15.31 & 13.61 & 10.41 & 5.53 & 17.41 & 33.46 & 30.06 & 13.44 & 3.70 & 4.90 & 3.43 & 7.64 & 12.67 & 5.94 \\
\hline & 11.94 & 9.71 & 14.58 & 5.90 & & 28.29 & 20.52 & 39.03 & 6.00 & 7.10 & 4.03 & & 16.48 & 19.75 \\
\hline & 8.10 & 10.17 & 14.41 & 5.23 & 12.81 & 45.84 & 38.53 & 32.49 & 4.97 & 7.60 & 5.23 & 6.47 & 19.82 & 13.51 \\
\hline \multirow[t]{3}{*}{ P02 } & 6.74 & 8.00 & 9.71 & 7.47 & 21.35 & 41.60 & 25.65 & 34.96 & 5.23 & 7.34 & 6.03 & 10.44 & 18.01 & 13.78 \\
\hline & 8.67 & 12.54 & 8.77 & 6.60 & 55.05 & 86.55 & 36.87 & 35.23 & 5.77 & 5.23 & 4.50 & 12.31 & 13.44 & 11.44 \\
\hline & 7.87 & 7.94 & 8.07 & 6.50 & 54.28 & 44.57 & 29.53 & 28.86 & 4.07 & 4.93 & 3.97 & 11.44 & 10.97 & 11.47 \\
\hline \multirow[t]{3}{*}{ P03 } & 8.20 & 8.37 & 8.14 & 6.97 & 45.84 & 38.90 & 48 & 22.45 & 80 & 4.83 & 4.97 & 11.67 & .08 & 9.71 \\
\hline & 11.87 & 8.97 & 8.80 & 7.10 & 74.20 & 40.14 & 64.56 & 20.18 & 4.83 & 5.13 & 4.20 & 16.31 & 12.87 & 7.97 \\
\hline & .84 & 10.14 & 8.20 & 6.64 & 27.46 & 30.16 & 45 & 16 & 5.63 & 4.90 & 4.43 & 11.21 & .70 & 5.96 \\
\hline \multirow[t]{3}{*}{ P04 } & 10.94 & & 7.10 & 6.37 & 29.59 & 28.96 & 52.38 & 17.28 & 6.03 & 3. & 4.00 & 9.80 & 12.01 & 7.40 \\
\hline & 6.23 & 5.97 & 7.64 & 4.23 & 17.88 & 13.44 & 29.43 & 16.41 & 3.37 & 3.37 & 2.97 & 5.50 & 5.97 & 5.83 \\
\hline & .14 & 5.83 & 6.30 & 3.70 & 13.11 & 71 & 17 & 7.80 & 23 & 3.33 & 2 & 5.6 & .57 & .43 \\
\hline \multirow[t]{3}{*}{ P05 } & 4.90 & 6.64 & 6.50 & 3.93 & 16.24 & 10.44 & 18.28 & 6.57 & 3.17 & 3.83 & 3.70 & 4.50 & 5.50 & 4.93 \\
\hline & .20 & 5.63 & 5.20 & 3.67 & 13.54 & 29.86 & 25.89 & 8.77 & 2.83 & 3.00 & 3.00 & 8.47 & 8.47 & 4.70 \\
\hline & 11.51 & 6.07 & 4.5 & 4.27 & 9.81 & 17. & 21 & & 2.50 & 3. & 2. & 6.8 & 6.80 & 4.83 \\
\hline \multirow[t]{3}{*}{ P06 } & 9.04 & 4.13 & 6.37 & 4.30 & 17.55 & 24.89 & 23.39 & 8.70 & 2.66 & 3.60 & 2.70 & 7.10 & 7.10 & 4.37 \\
\hline & 8.97 & 5.63 & 7.44 & 4.57 & 14.61 & 18.95 & 11.71 & 13.57 & 3.60 & 3.27 & 3.57 & 5.2 & 7.00 & 5.67 \\
\hline & 6.24 & 4.43 & 6.20 & 3.20 & 11.14 & 23.05 & 18. & 6.94 & 3.67 & 3.5 & 2.83 & 8.2 & 7.17 & 4.97 \\
\hline \multirow[t]{3}{*}{ P07 } & 5.47 & 5.73 & 5.67 & 4.30 & 9.37 & 13.11 & 13.14 & 11.04 & 3.13 & 4.00 & 3.06 & 5.87 & 5.97 & 7.07 \\
\hline & 13.74 & 7. & 11.91 & 8.40 & 97.15 & 36.8 & 28. & 42.90 & & 4. & 6.24 & 19.1 & 11.21 & 12.27 \\
\hline & 12.67 & 7.87 & 11.01 & 7.44 & 38.67 & 31.16 & 27.76 & 21.68 & 6.50 & 5.20 & 5.94 & 23.05 & 9.14 & 10.14 \\
\hline \multirow[t]{3}{*}{ P08 } & 11.24 & 8.34 & 9.44 & 7.20 & 43.34 & 25.02 & 24.52 & 20.42 & 5.47 & 5.70 & 7.50 & 15.54 & 9.71 & 10.07 \\
\hline & 12.01 & & 10.44 & 9.34 & 19.08 & 19.45 & 56.02 & 15.08 & 5.73 & 5.2 & 5.73 & 8.9 & 8.67 & 8.54 \\
\hline & 13.88 & 10.94 & 10.97 & 8.34 & 17.75 & 20.28 & 18.18 & 23.82 & 5.13 & 5.10 & 5.83 & 8.54 & 8.57 & 9.54 \\
\hline \multirow[t]{3}{*}{ P09 } & 12.78 & 9.67 & 9.34 & 9.14 & 19.95 & 17.81 & 16.21 & 15.95 & 5.13 & 4.73 & 5.60 & 8.44 & 8.40 & 9.50 \\
\hline & 10.74 & 11.91 & 13.61 & 9.81 & 34.83 & 36.37 & 41.24 & 43.37 & 4.47 & 5.60 & 6.94 & 12.74 & 17.41 & 24.18 \\
\hline & 13.38 & & & 8.87 & 33.40 & 40.94 & 32.90 & 20.58 & 4.50 & 6.07 & 6.94 & 14.11 & 16.71 & 15.61 \\
\hline \multirow[t]{3}{*}{ P10 } & 12.47 & 13.11 & 13.54 & 9.70 & 30.73 & 31.26 & 52.38 & 20.23 & 4.70 & 5.67 & 5.70 & 12.77 & 18.98 & 14.73 \\
\hline & 8.04 & 4. & 7.47 & 3.87 & 24.35 & 16.41 & 26.59 & 12.94 & 3.80 & 3.43 & 2.70 & $6.8^{\prime}$ & 6.27 & 7.44 \\
\hline & 7.54 & 3.57 & 6.77 & 4.83 & 22.75 & 30.96 & 22.62 & 19.48 & 4.17 & 3.06 & 3.13 & 9.77 & 7.44 & 7.00 \\
\hline 111 & 8.74 & 4.10 & 9.57 & 4.00 & 31.23 & 29.52 & 20.68 & 19.68 & 3.57 & 3.33 & 2.73 & 7.00 & 6.67 & 6.74 \\
\hline
\end{tabular}




\section{Stroke Count}

\begin{tabular}{|c|c|c|c|c|c|c|c|c|c|c|c|c|c|}
\hline & \multicolumn{8}{|c|}{ SNOW } & \multicolumn{5}{|c|}{ BARE } \\
\hline & SO & \multicolumn{2}{|c|}{ Flat } & & & $\begin{array}{r}\text { Inc } \\
\text { PN }\end{array}$ & $\begin{array}{r}\text { cline } \\
\text { WB }\end{array}$ & FW & & $\begin{array}{l}\text { Flat } \\
\text { PN }\end{array}$ & t FW & $\begin{array}{c}\text { Incl } \\
\text { SO }\end{array}$ & $\begin{array}{l}\text { line } \\
\text { FW }\end{array}$ \\
\hline & 9 & 11 & 11 & 6 & 11 & 19 & 19 & 9 & 3 & 4 & 3 & 4 & 6 \\
\hline & 8 & 10 & 11 & 5 & 10 & 13 & 11 & 9 & 4 & 5 & 4 & 5 & 5 \\
\hline P01 & 9 & 9 & 8 & 6 & 9 & 12 & 16 & 10 & 4 & 6 & 4 & 4 & 6 \\
\hline & 13 & 9 & 12 & 7 & & 14 & 14 & 13 & 6 & 7 & 4 & & 12 \\
\hline & 10 & 9 & 10 & 7 & & 19 & 14 & 14 & 6 & 6 & 5 & & 8 \\
\hline P02 & 8 & 8 & 11 & 7 & & 16 & 15 & 16 & 5 & 7 & 5 & & 8 \\
\hline & 8 & 9 & 9 & 7 & 21 & 17 & 16 & 17 & 6 & 5 & 5 & 8 & 7 \\
\hline & 8 & 8 & 8 & 7 & 18 & 19 & 16 & 12 & 4 & 5 & 5 & 8 & 8 \\
\hline P03 & 8 & 8 & 7 & 7 & 19 & 17 & 20 & 10 & 5 & 5 & 6 & 8 & 7 \\
\hline & 11 & 10 & 10 & 7 & 16 & 21 & 23 & 11 & 5 & 7 & 4 & 12 & 8 \\
\hline & 11 & 12 & 9 & 7 & 16 & 18 & 21 & 11 & 7 & 6 & 5 & 10 & 6 \\
\hline P04 & 10 & 9 & 8 & 7 & 18 & 16 & 23 & 11 & 4 & 4 & 4 & 9 & 6 \\
\hline & 6 & 6 & 6 & 4 & 12 & 9 & 9 & 11 & 3 & 2 & 3 & 4 & 4 \\
\hline & 6 & 6 & 6 & 4 & 9 & 7 & 9 & 8 & 2 & 3 & 3 & 4 & 5 \\
\hline P05 & 5 & 5 & 6 & 4 & 8 & 6 & 11 & 7 & 3 & 3 & 3 & 4 & 5 \\
\hline & 6 & 6 & 6 & 4 & 10 & 14 & 11 & 9 & 3 & 2 & 2 & 6 & 6 \\
\hline & 11 & 6 & 5 & 5 & 10 & 12 & 9 & 9 & 3 & 3 & 2 & 6 & 6 \\
\hline P06 & 8 & 4 & 6 & 4 & 11 & 11 & 12 & 10 & 3 & 2 & 2 & 6 & 6 \\
\hline & 9 & 6 & 6 & 5 & 9 & 10 & 11 & 11 & 4 & 3 & 3 & 4 & 5 \\
\hline & 8 & 5 & 5 & 3 & 10 & 14 & 10 & 8 & 5 & 3 & 2 & 5 & 5 \\
\hline P07 & 7 & 6 & 5 & 4 & 9 & 10 & 10 & 9 & 2 & 3 & 2 & 4 & 5 \\
\hline & 10 & 9 & 10 & 8 & 15 & 18 & 15 & 16 & 6 & 5 & 5 & 9 & 10 \\
\hline & 11 & 9 & 9 & 8 & 15 & 15 & 14 & 12 & 6 & 4 & 5 & 12 & 9 \\
\hline P08 & 10 & 8 & 10 & 8 & 16 & 14 & 13 & 12 & 4 & 5 & 5 & 10 & 8 \\
\hline & 8 & 7 & 6 & 6 & 9 & 10 & 11 & 8 & 5 & 4 & 5 & 6 & 6 \\
\hline & 7 & 6 & 7 & 5 & 9 & 8 & 9 & 9 & 4 & 4 & 4 & 6 & 6 \\
\hline P09 & 8 & 6 & 6 & 5 & 9 & 8 & 9 & 8 & 5 & 3 & 4 & 6 & 6 \\
\hline & 7 & 6 & 5 & 6 & 13 & 13 & 13 & 12 & 3 & 4 & 5 & 6 & 9 \\
\hline & 8 & 6 & 6 & 6 & 15 & 14 & 12 & 9 & 2 & 4 & 5 & 6 & 6 \\
\hline P10 & 8 & 6 & 6 & 5 & 12 & 12 & 11 & 9 & 3 & 4 & 3 & 7 & 6 \\
\hline & 6 & 5 & 6 & 4 & 15 & 10 & 10 & 8 & 4 & 3 & 3 & 6 & 5 \\
\hline & 7 & 3 & 5 & 5 & 12 & 12 & 9 & 10 & 4 & 2 & 3 & 7 & 6 \\
\hline P11 & 8 & 4 & 6 & 4 & 12 & 11 & 13 & 8 & 3 & 3 & 3 & 5 & 5 \\
\hline
\end{tabular}


Impulse $(\% *$ s)

\begin{tabular}{|c|c|c|c|c|c|c|c|c|c|c|c|c|c|c|}
\hline & \multicolumn{8}{|c|}{ SNOW } & \multicolumn{6}{|c|}{ BARE } \\
\hline & \multicolumn{4}{|c|}{ Flat } & \multicolumn{4}{|c|}{ Incline } & \multicolumn{4}{|c|}{ Flat } & \multicolumn{2}{|l|}{ Incline } \\
\hline & SO & PN & WB & FW & SO & PN & WB & FW & SO & PN & FW & SO & PN & FW \\
\hline$\overline{\mathrm{P} 03}$ & 8.575 & 6.570 & 4.018 & 10.604 & 125.503 & 130.997 & 61.800 & 66.342 & 2.405 & 0.807 & 0.765 & 18.686 & 26.706 & 17.908 \\
\hline P04 & 31.020 & 30.499 & 14.565 & 15.637 & 202.649 & 185.957 & 379.550 & 149.772 & 9.533 & 16.214 & 10.792 & 53.870 & 66.493 & 86.194 \\
\hline P05 & 41.689 & 30.528 & 50.215 & 16.774 & 88.059 & 101.462 & 132.066 & 76.548 & 24.598 & 28.192 & 16.593 & 19.931 & 78.026 & 31.735 \\
\hline P06 & 66.789 & 33.947 & 32.072 & 45.384 & 169.350 & 528.603 & 171.701 & 166.421 & 10.638 & 23.789 & 9.844 & 56.462 & 141.772 & 74.135 \\
\hline P07 & 31.801 & 18.246 & 23.590 & 9.130 & 110.147 & 65.930 & 57.261 & 112.392 & 16.042 & 7.016 & 10.514 & 61.416 & 32.879 & 55.482 \\
\hline P09 & 9.248 & 5.858 & 12.183 & 4.721 & 28.652 & 33.679 & 131.175 & 26.912 & 2.124 & 1.487 & 2.482 & 8.104 & 5.506 & 9.663 \\
\hline P10 & 50.959 & 34.947 & 29.983 & 37.485 & 409.548 & 406.781 & 244.274 & 157.494 & 10.333 & 4.855 & 23.998 & 97.028 & 132.930 & 52.990 \\
\hline P11 & 35.199 & 24.059 & 51.906 & 25.259 & 414.117 & 254.271 & 338.344 & 249.029 & 11.673 & 11.760 & 5.684 & 49.783 & 42.571 & 44.109 \\
\hline
\end{tabular}




\section{Static Resistance (N)}

Condition
\begin{tabular}{|l|r|r|}
\hline BL1 & \multicolumn{1}{c}{ Flat } & \multicolumn{1}{c}{ Incline } \\
\hline BL2 & 28.124 & 178.113 \\
\hline BL3 & 33.593 & 172.741 \\
\hline SO1 & 209.409 & 187.560 \\
\hline SO2 & 149.429 & 292.597 \\
\hline SO3 & 105.292 & 298.043 \\
\hline PN1 & 86.066 & 318.615 \\
\hline PN2 & 119.205 & 307.052 \\
\hline PN3 & 101.354 & 302.762 \\
\hline FW1 & 118.055 & 322.300 \\
\hline FW2 & 148.425 & 267.127 \\
\hline FW3 & 145.607 & 247.959 \\
\hline WB1 & 152.344 & 249.402 \\
\hline WB2 & 114.555 & 267.332 \\
\hline WB3 & 122.900 & 287.874 \\
\hline
\end{tabular}




Kinetic Resistance
Condition Flat
\begin{tabular}{|l|r|r|}
\hline BL1 & 9.114 & 133.125 \\
\hline BL2 & 9.327 & 141.403 \\
\hline BL3 & 9.188 & 133.367 \\
\hline SO1 & 83.943 & 232.437 \\
\hline SO2 & 66.641 & 206.719 \\
\hline SO3 & 53.801 & 214.031 \\
\hline PN1 & 33.468 & 218.254 \\
\hline PN2 & 35.645 & 213.906 \\
\hline PN3 & 39.262 & 207.943 \\
\hline FW1 & 37.672 & 185.519 \\
\hline FW2 & 45.794 & 199.784 \\
\hline FW3 & 41.928 & 202.620 \\
\hline WB1 & 50.678 & 201.374 \\
\hline WB2 & 51.735 & 192.905 \\
\hline WB3 & 46.779 & 197.299 \\
\hline
\end{tabular}




\section{Flat Condition: Penetration (mm)}

\begin{tabular}{|c|c|c|c|}
\hline \multirow[t]{2}{*}{ Condition } & \multicolumn{3}{|c|}{ Collection area Left penetration Right penetration } \\
\hline & Entrance & 0 & 0 \\
\hline \multirow{3}{*}{ BL1 } & Middle & 0 & 0 \\
\hline & Final & 0 & 0 \\
\hline & Entrance & 0 & 0 \\
\hline \multirow{3}{*}{ BL2 } & Middle & 0 & 0 \\
\hline & Final & 0 & 0 \\
\hline & Entrance & 0 & 0 \\
\hline \multirow[b]{2}{*}{ BL3 } & Middle & 0 & 0 \\
\hline & Final & 0 & 0 \\
\hline \multirow{4}{*}{ SO1 } & Entrance & 9.5 & 9 \\
\hline & Middle & 11 & 10 \\
\hline & Final & 10.5 & 10 \\
\hline & Entrance & 11.5 & 11.5 \\
\hline \multirow{3}{*}{$\mathrm{SO} 2$} & Middle & 16 & 14 \\
\hline & Final & 15 & 15 \\
\hline & Entrance & 13 & 11 \\
\hline \multirow[b]{2}{*}{$\mathrm{SO} 3$} & Middle & 13 & 12 \\
\hline & Final & 10.5 & 11 \\
\hline \multirow{4}{*}{ PN1 } & Entrance & 5.5 & 4.5 \\
\hline & Middle & 4 & 18 \\
\hline & Final & 0 & 3 \\
\hline & Entrance & 7.5 & 4.5 \\
\hline \multirow{3}{*}{ PN2 } & Middle & 3 & 2 \\
\hline & Final & 1.5 & 1.5 \\
\hline & Entrance & 6.5 & 3.5 \\
\hline \multirow[b]{2}{*}{ PN3 } & Middle & 1 & 3 \\
\hline & Final & 8 & 9 \\
\hline \multirow{4}{*}{ FW1 } & Entrance & 2.5 & \\
\hline & Middle & 2 & \\
\hline & Final & 1.5 & \\
\hline & Entrance & 1 & \\
\hline \multirow{3}{*}{ FW2 } & Middle & 2.5 & \\
\hline & Final & 0.5 & \\
\hline & Entrance & 0 & \\
\hline \multirow[b]{2}{*}{ FW3 } & Middle & 0 & \\
\hline & Final & 0.5 & \\
\hline \multirow{4}{*}{ WB1 } & Entrance & 4.5 & 0 \\
\hline & Middle & 1.5 & 1.5 \\
\hline & Final & 0 & 0 \\
\hline & Entrance & 0 & 0 \\
\hline \multirow{4}{*}{ WB2 } & Middle & 0 & 2 \\
\hline & Final & 1.5 & 0 \\
\hline & Entrance & 2 & 0 \\
\hline & Middle & 1 & 1.5 \\
\hline WB3 & Final & 0 & 1 \\
\hline
\end{tabular}




\section{Incline Condition: Penetration (mm)}

\begin{tabular}{|c|c|c|c|}
\hline Condition & \multicolumn{3}{|c|}{ Collection area Left Penetration Right Penetration } \\
\hline \multirow{4}{*}{ BL1 } & Entrance & 0 & 0 \\
\hline & Middle & 0 & 0 \\
\hline & Final & 0 & 0 \\
\hline & Entrance & 0 & 0 \\
\hline \multirow{3}{*}{ BL2 } & Middle & 0 & 0 \\
\hline & Final & 0 & 0 \\
\hline & Entrance & 0 & 0 \\
\hline \multirow[b]{2}{*}{ BL3 } & Middle & 0 & 0 \\
\hline & Final & 0 & 0 \\
\hline \multirow{4}{*}{ SO1 } & Entrance & 7.5 & 7.5 \\
\hline & Middle & 14 & 12.5 \\
\hline & Final & 15.5 & 16 \\
\hline & Entrance & 8 & 8 \\
\hline \multirow{3}{*}{$\mathrm{SO} 2$} & Middle & 12.5 & 13 \\
\hline & Final & 12.5 & 13 \\
\hline & Entrance & 10 & 9 \\
\hline \multirow[b]{2}{*}{$\mathrm{SO} 3$} & Middle & 14 & 15.5 \\
\hline & Final & 8 & 9 \\
\hline \multirow{4}{*}{ PN1 } & Entrance & 0 & 0 \\
\hline & Middle & 0 & 0.5 \\
\hline & Final & 9 & 10 \\
\hline & Entrance & 8 & 7 \\
\hline \multirow{3}{*}{ PN2 } & Middle & 2.5 & 3.5 \\
\hline & Final & 11.5 & 10.5 \\
\hline & Entrance & 5 & 8.5 \\
\hline \multirow[b]{2}{*}{ PN3 } & Middle & 7 & 8 \\
\hline & Final & 5.5 & 8.5 \\
\hline \multirow{4}{*}{ FW1 } & Entrance & 2.5 & \\
\hline & Middle & 10.5 & \\
\hline & Final & 13.5 & \\
\hline & Entrance & 5.5 & \\
\hline \multirow{3}{*}{ FW2 } & Middle & 8 & \\
\hline & Final & 10.5 & \\
\hline & Entrance & 8.5 & \\
\hline \multirow[b]{2}{*}{ FW3 } & Middle & 1 & \\
\hline & Final & 10.5 & \\
\hline \multirow{4}{*}{ WB1 } & Entrance & 0 & 0 \\
\hline & Middle & 2.5 & 0 \\
\hline & Final & 0 & 0 \\
\hline & Entrance & 0 & 7.5 \\
\hline \multirow{4}{*}{ WB2 } & Middle & 2.5 & 0 \\
\hline & Final & 4 & 0 \\
\hline & Entrance & 8 & 5 \\
\hline & Middle & 2.5 & 3 \\
\hline WB3 & Final & 5 & 0 \\
\hline
\end{tabular}

